\title{
Long non-coding RNA GAS5 regulates myocardial ischemia-reperfusion injury through the PI3K/AKT apoptosis pathway by sponging miR-532-5p
}

\author{
YANG HAN $^{1}$, NAN WU $^{2}$, FEI XIA $^{3}$, SHUANG LIU $^{1}$ and DALIN JIA ${ }^{1}$ \\ ${ }^{1}$ Department of Cardiology and ${ }^{2}$ The Central Laboratory, The First Affiliated Hospital of China Medical University, Shenyang, \\ Liaoning 110001; ${ }^{3}$ Department of Cardiology, Liaoning Provincial People's Hospital, Shenyang, Liaoning 110000, P.R. China
}

Received July 29, 2019; Accepted December 2, 2019

DOI: $10.3892 /$ ijmm.2020.4471

\begin{abstract}
Long non-coding RNAs (lncRNAs) have been revealed to have a marked effect in cardiovascular diseases, including during cardiac development, cardiac hypertrophy, myocardial fibrosis and myocardial ischemic injury. The mechanism of myocardial ischemia-reperfusion injury (MIRI) is very complicated. Although studies have confirmed that lncRNAs are involved, the specific mechanism remains largely unknown. The lncRNA growth arrest specific 5 (GAS5) is known as a regulator of a number of diseases, including certain cancer types. The present study aimed to investigate the function of lncRNA GAS5 in MIRI. The present study reported that the expression of lncRNA GAS5 in $\mathrm{H} 9 \mathrm{c} 2$ cells treated with anoxia and reoxygenation was significantly upregulated compared with the control group $(\mathrm{P}<0.05)$. Similarly, the expression of lncRNA GAS5 in myocardial tissue obtained from rats treated with MIRI was significantly upregulated compared with the untreated controls $(\mathrm{P}<0.05)$. Silencing of lncRNA GAS5 was able to attenuate myocardial damage, as cell viability increased and the apoptosis rate decreased. Classical apoptotic proteins involved in MIRI, including B-cell lymphoma 2, Bcl-2-associated X protein and cleaved caspase-3, also exhibited the same trend. At the same time, when lncRNA GAS5 was silenced, microRNA (miR)-532-5p, which was originally expressed at the stage of injury, was upregulated. The luciferase reporter assay results indicated that the IncRNA GAS5 functioned as a molecular sponge of miR-532-5p. The gain- and loss-of-function analysis of miR-532-5p indicated that it was involved in the regulation of MIRI; the trend of results following its overexpression was
\end{abstract}

Correspondence to: Professor Dalin Jia, Department of Cardiology, The First Affiliated Hospital of China Medical University, 155 North Nanjing Street, Heping, Shenyang, Liaoning 110001, P.R. China E-mail: jd12001@126.com

Key words: long non-coding RNA growth arrest specific 5, microRNA-532-5p, phosphatase and tensin homolog, myocardial ischemia-reperfusion injury, apoptosis also consistent with the trend observed following the silencing of lncRNA GAS5. Notably, the protective effect of lncRNA GAS5 silencing on cells was attenuated by miR-532-5p inhibition. Phosphatase and tensin homolog was revealed to be a key target gene for the function of lncRNA GAS5, and its regulation was achieved via binding to miR-532-5p. In other words, silencing lncRNA GAS5 ultimately promoted the activation of the phosphoinositide-3-kinase (PI3K)/protein kinase B pathway (AKT) to reduce myocardial damage. Therefore, IncRNA GAS5 was able to regulate MIRI through the PI3K/AKT apoptosis pathway by sponging miR-532-5p.

\section{Introduction}

Coronary heart disease is the most common type of cardiovascular disease. Myocardial infarction is the most dangerous pathological process, and reperfusion of the coronary artery is the most fundamental treatment (1). With the development of coronary thrombolysis, percutaneous coronary intervention, coronary artery bypass grafting and other treatments, myocardial necrosis may be prevented, saving the lives of numerous patients with myocardial infarction (2). However, the reperfusion of the coronary vessels subsequent to myocardial ischemia and infarction itself may also cause reperfusion injury that aggravates myocardial cell damage or even causes necrosis $(3,4)$. This phenomenon is myocardial ischemic-reperfusion injury (MIRI) (5). The mechanism of MIRI is very complex. Previous studies have reported that ischemia-reperfusion is able to induce oxidative stress, intracellular calcium overload, the rapid recovery of physiological $\mathrm{pH}$, an inflammatory response, further active cell apoptosis, necrosis and autophagy, eventually resulting in further damage to the myocardium (6-8). However, it is recognized that MIRI may be alleviated through regulation of the apoptotic pathway. Multiple apoptotic pathways, including the phosphoinositide-3-kinase (PI3K)/protein kinase B (AKT) pathway, are activated and involved in MIRI $(9,10)$. Research on the molecular mechanisms of MIRI is still being conducted; the effective prevention and treatment of MIRI is a difficult problem and a focus of research (11). Current research trends in the field of life sciences have shifted from the protein level to the gene regulation level, and from protein-coding genes to non-protein-coding protein genes (12). 
Long-non-coding RNA (lncRNA) is most commonly defined as a transcript with a length of $>200$ nucleotides and no protein encoding function, and is distributed in the nucleus and the cytoplasm (13). IncRNA has been revealed to be involved in the pathophysiological processes of various tumor types, including in cell growth, proliferation, invasion and apoptosis $(14,15)$. A number of studies have considered the effects of lncRNAs that serve functions in myocardial ischemia $(16,17)$. A number of lncRNAs have been reported to be involved in the regulation of myocardial ischemia by exerting their biological mechanisms $(18,19)$. However, there are few reports on the function of lncRNAs in an MIRI model. A previous study performed biological analyses of a MIRI model in mice, and revealed that various lncRNAs are differentially expressed, and it was predicted that MIRI may be regulated by their participation in biological processes (20). The investigation of individual lncRNA functions is still ongoing. It is important to study the function of lncRNAs in MIRI.

Schneider et al (21) discovered upregulated lncRNA growth arrest specific 5 (GAS5) in growth-arrested cells screened by subtractive hybridization in 1988. The coding gene for GAS5 is a member of the 5 ' terminal oligopyrimidine family, containing 12 exons, and its potential open reading frame is very limited $(22,23)$. Various studies have suggested that lncRNA GAS5 is expressed in a variety of tumor tissues and serves the function of a tumor suppressor gene (24-26).

Overexpression of IncRNA GAS5 may inhibit the growth, invasion and metastasis of tumor cells and induce apoptosis (27). However, the mechanism of action of lncRNA GAS5 in MIRI is still unclear. The present study focused on the potential regulatory function of lncRNA GAS5 in MIRI, particularly in regulating apoptosis. It was proposed that IncRNA GAS5 may regulate apoptosis induced by MIRI via the PI3K/AKT pathway by binding to microRNA (miR)-532-5p. The aim of the present study was to provide a preventive strategy for MIRI.

\section{Materials and methods}

Cell culture and hypoxia-reoxygenation $(H R)$ model. Rat cardiomyocte H9c2 cells were purchased from the Shanghai Institutes for Biological Sciences, Chinese Academy of Sciences (Shanghai, China). H9c2 cells were cultured in Dulbecco's modified Eagle's medium (DMEM; Gibco; Thermo Fisher Scientific, Inc.) containing 10\% fetal bovine serum (FBS; Tianjin Hao Yang Biological Company) at $37^{\circ} \mathrm{C}$ in an incubator with $95 \%$ air and $5 \% \mathrm{CO}_{2}$. Then, a $\mathrm{H} 9 \mathrm{c} 2 \mathrm{HR}$ injury model was prepared to mimic the MIRI model in vitro. In brief, the cells were cultured with glucose-free DMEM and incubated in a low-oxygen atmosphere $\left(90 \% \mathrm{~N}_{2}, 5 \% \mathrm{CO}_{2}\right.$ and $5 \% \mathrm{O}_{2} ; 37^{\circ} \mathrm{C}$ ) for $8 \mathrm{~h}$. Subsequently, the medium was changed to DMEM containing $10 \% \mathrm{FBS}$ in a normal atmosphere (95\% air and $5 \% \mathrm{CO}_{2} ; 37^{\circ} \mathrm{C}$ ) for $2 \mathrm{~h}$.

Animals and MIRI model. A total of 20 healthy male (age, 6-8 weeks) specific pathogen-free (SPF) Wistar rats weighing $300 \pm 20 \mathrm{~g}$, were purchased from Liaoning Changsheng Biotechnology Co., Ltd. The rats were treated according to the Guide for the Care and Use of Laboratory Animals (Federal Register Doc. 2011.11490; National Institutes of
Health, Bethesda, MD, USA) (28). The rats were maintained in a clean and ventilated environment at a temperature of $22-24^{\circ} \mathrm{C}$ indoors. Fresh food and drinking water were available ad libitum, with a circadian rhythm of $12 \mathrm{~h}$. Food and bedding were changed for the rats every other day, and the health of the animals was monitored. The 20 rats were randomly divided into a control group (without any treatment) and an ischemia-reperfusion group. Preparation of the isolated rat heart MIRI model was performed using the Langendorff isolated cardiac perfusion system (29). A peritoneal injection of pentobarbital sodium $(30 \mathrm{mg} / \mathrm{kg}$ ) was administered for anesthesia; the anesthetized rats were fixed to a table, the chest was quickly opened, the intact heart was removed and placed in a $4^{\circ} \mathrm{C} \mathrm{KH}$ solution $(\mathrm{NaCl} 0.15 \mathrm{~mol} / 1, \mathrm{KCl} 0.006 \mathrm{~mol} / 1$, $\mathrm{CaCl}_{2} 0.002 \mathrm{~mol} / \mathrm{l}$ and $\mathrm{NaHCO}_{3} 0.002 \mathrm{~mol} / \mathrm{l}$ ) with pre-filled $95 \% \mathrm{O}_{2}+5 \% \mathrm{CO}_{2}$ mixed gas, and then the surrounding tissue was carefully removed and the aorta exposed. The aorta was carefully lifted with forceps in order to insert the perfusion tube. Once the heart began to fluctuate, it was fixed to the cardiac perfusion device with a 7-0 surgical line near the upper edge of the aorta. The isolated rat heart was perfused with $\mathrm{KH}$ solution using a perfusion device and stabilized for $10 \mathrm{~min}$ prior to the induction of ischemia. The perfusion conditions were maintained at a constant temperature of $37^{\circ} \mathrm{C}$ and a constant pressure of $75 \mathrm{mmHg}$. Then, the perfusion was stopped, and the MIRI model was prepared by stopping the perfusion for $30 \mathrm{~min}$ and reperfusing for $120 \mathrm{~min}$. Rats were sacrificed by cervical dislocation at the end of reperfusion for $120 \mathrm{~min}$, and no additional anesthetic dose was required. At the end of the experiment, the rat had the heart removed and no heartbeat. In addition, the rats had no breathing, no pupils and nerve reflexes, and had finally succumbed to mortality. Animal experiments were ethically approved by the experimental animal welfare and ethics committee of China Medical University (Liaoning, China; approval no. kt2018009). Animal studies were conducted according to the checklist of the ARRIVE guidelines (30).

Cell transfection. Small interfering RNAs (siRNAs) targeting GAS5 (siGAS5) and the negative control siRNAs (si-NC) were designed and synthesized by Shanghai GenePharma Co., Ltd. The sequences were as follows: siGAS5 (rat) sense, 5'-TCTCACAGGCAGTTCTGTGG-3' and antisense, 5'-ATC CATCCAGTCACCTCTGG-3; si-NC (rat) sense, 5'-UUCUCC GAACGUGUCACGUTT-3' and antisense, 5'-CGUGACACG UUCGGAGAATT-3'. miR-532-5p mimics/inhibitors and their negative control were synthesized by Shanghai GenePharma Co., Ltd. The sequences were as follows: miR-532-5p mimics (rat), 5'-CAUGCCUUGAGUGUAGGACUGUAGUCCUAC ACUCAAGGCAUGUU-3'; and miR-532-5p inhibitor (rat), 5'-ACAGUCCUACUCAAGGCAUG-3'; miRNA inhibitor NC, 5'-CAGUACUUUUGUGUAGUACAA-3 and microRNA mimic NC, 5'-UUCUCCGAACGUGUCACGUTT-3. For transfection, $\mathrm{H} 9 \mathrm{c} 2$ cells were cultured to achieve a density of $70 \%$, and transfected using Lipofectamine ${ }^{\circledR} 3000$ reagent (Invitrogen; Thermo Fisher Scientific, Inc.), according to the manufacturer's protocol. The quantity of siRNA transfected was as follows: $75 \mathrm{pmol} / \mathrm{well}$ in 6-well plates, $30 \mathrm{pmol} / \mathrm{well}$ in 12 -well plates and $3 \mathrm{pmol} / \mathrm{well}$ in 96 -well plates. After transfection for 24 or $48 \mathrm{~h}$ at $37^{\circ} \mathrm{C}$ in an incubator containing 
$5 \% \mathrm{CO}_{2}$, the cells were subjected to HR experiments, followed by the subsequent experiments. Transfections were performed in 6-, 12- or 96-well plates according to the requirements of each experiment.

Cell counting kit-8 (CCK-8) assay. To investigate the effect of IncRNA GAS5 on cell viability in MIRI, a CCK-8 assay was used. The $\mathrm{H} 9 \mathrm{c} 2$ cells $\left(3 \times 10^{3}\right.$ cells/well) were cultured in 96-well plates according to the experimental groups, and then cell viability was determined using a CCK-8 assay (Dojindo Molecular Technologies, Inc.), according to the manufacturer's protocol. Subsequent to treating the cells according to the predetermined experimental groups, $10 \mu \mathrm{l} \mathrm{CCK}-8$ solution was added to each well and incubated for $1 \mathrm{~h}$ at $37^{\circ} \mathrm{C}$ in a $5 \% \mathrm{CO}_{2}$ incubator. The absorbance value was detected at a wavelength of $450 \mathrm{~nm}$ by an ultra-micro microporous plate spectrophotometer (BioTek Instruments, Inc.).

Measurement of myocardial injury markers. The H9c2 cells $\left(3 \times 10^{3}\right.$ cells/well) were cultured in 96-well culture plates to detect myocardial enzyme markers. Lactate dehydrogenase $(\mathrm{LDH})$ and creatine kinase isoenzyme (CK-MB) may be released into the culture medium following myocardial cell injury and death, and their levels may be tested to indicate the degree of damage to cardiomyocytes (31). LDH was determined using an LDH assay kit (Shenyang Wan Biotechnology Co., Ltd.) according to the manufacturer's protocol. The levels of CK-MB in the culture medium were measured using a CK-MB enzyme-linked immunosorbent assay kit (cat. no. MB-6930A; Jiangsu MB Biotechnology Co., Ltd.) according to the manufacturer's protocol. The absorbance value was detected at a wavelength of $450 \mathrm{~nm}$ by an ultra-micro microporous plate spectrophotometer (BioTek Instruments, Inc.).

Measurement of cell apoptosis. The degree of cell apoptosis was visually measured using a Hoechst staining kit (Beyotime Institute of Biotechnology) according to the manufacturer's protocol. H9c2 cells $\left(1 \times 10^{5}\right.$ cells/well) were plated in 12-well plates. The cells were transfected and treated by HR according to the experimental group. The treated cells were fixed with $4 \%$ paraformaldehyde at room temperature for $20 \mathrm{~min}$, washed with PBS and stained with a Hoechst stain for 20 min at room temperature. Then, the nuclear morphology of the cells was detected at a $\times 400$ magnification under a fluorescence microscope (Image-Pro Plus version 6.0; Media Cybernetics, Inc., Rockville, MD, USA). The number of apoptotic cells was counted with the naked eye, and the quantitative index of apoptosis was expressed as the percentage of apoptotic cells in the total cells. A more accurate rate of cell apoptosis was determined using flow cytometry analysis (LSRFortessa; BD Biosciences, Franklin Lakes, NJ, USA) using the Annexin V fluorescein isothiocyanate/propidium iodide kit (Nanjing KeyGen Biotech Co., Ltd., Nanjing, China) to label the cells, according to the manufacturer's protocol. SPSS version 23.0 (SPSS, Inc., Chicago, IL, USA) was used for data analysis.

Target identification and luciferase reporter assay. RNAhybrid and Targetscan online software were used to identify the downstream target genes of lncRNA GAS5, RNAhybrid software (RNAhybrid-2.1.2; https://bibiserv.cebitec.uni-bielefeld. de/rnahybrid/) can predict the binding of lncRNA and miRNA, and Targetscan (release 3.1; http://www.targetscan. org) can predict the binding of miRNA and mRNA. 293T cells purchased from The Cell Bank of Type Culture Collection of the Chinese Academy of Sciences and cultured in 96-well plate $\left(1.0 \times 10^{4}\right.$ cells/well) with DMEM (Gibco; Thermo Fisher Scientific, Inc.) at $37^{\circ} \mathrm{C}$ and $5 \% \mathrm{CO}_{2}$ for $24 \mathrm{~h}$. In order to detect the binding of GAS5 and miR-532-5p, 293T cells were co-transfected with pmiR-RB-Report ${ }^{\mathrm{TM}} \mathrm{r}$-Gas5(NR_002704.1 complete sequence)-WT(r-Gas5-WT)-or pmiR-RB-Report ${ }^{\mathrm{TM}}$ r-Gas5(NR_002704.1 complete sequence)-MUT(249-255:AA GGCAT $>$ TTCCGTA) (r-Gas5-MUT) luciferase reporter plasmids (Guangzhou RiboBio Co., Ltd., Guangzhou, China) along with miR-532-5p mimic (50 nM) or miR-532-5p mimic negative control $(50 \mathrm{nM})$ using Lipofectamine ${ }^{\circledR} 3000$ (Invitrogen; Thermo Fisher Scientific, Inc.) at room temperature. To detect the binding of phosphatase and tensin homolog (PTEN) and miR-532-5p, 293T cells were co-transfected with pmiR-RB-Rep ort $^{\mathrm{TM}} \mathrm{r}$-Pten(3'UTR:1310-3809)-WT (r-Pten-WT) or pmiR-RB-R eport ${ }^{\mathrm{TM}} \mathrm{r}$-Pten(3'UTR:1310-3809)-MUT(1352-1358 AAGGCAT $>$ TTCCGTA2584-2590AAGGCAT>TTCCGTA3730-3736AA GGCAT>TTCCGTA) (r-Pten-MUT) luciferase reporter plasmid along with miR-532-5p mimic (50 nM) or miR-532-5p mimic negative control $(50 \mathrm{nM})$. A total of $48 \mathrm{~h}$ after transfection, the luciferase activities were examined using the Dual-Luciferase Reporter Assay system (Promega Corporation, Madison, WI, USA) according to the manufacturer's protocol.

Western blotting. At $48 \mathrm{~h}$ post-transfection, H9c2 cells were treated with HR, and then protein was extracted with radioimmunoprecipitation assay lysis buffer (Beyotime Institute of Biotechnology). The total protein was extracted from lysates by centrifugation at $13,000 \mathrm{x} \mathrm{g}$ and $4^{\circ} \mathrm{C}$ for $15 \mathrm{~min}$. The concentration of protein was measured using a BCA protein concentration kit (Beyotime Institute of Biotechnology). For the western blotting, $40 \mu \mathrm{g}$ protein denatured by heating was subjected to $10 \%$ SDS-polyacrylamide gel electrophoresis for separation and then transferred to polyvinylidene difluoride (PVDF) membranes. The membrane was blocked using 5\% skim milk for $1 \mathrm{~h}$ at room temperature and then incubated overnight at $4^{\circ} \mathrm{C}$ with the specific primary antibodies, including anti-B-cell lymphoma 2 (Bcl-2; cat. no. WL01556; 1:500; Shenyang Wan Biotechnology Co., Ltd.), anti-Bcl-2-associated X protein (Bax; cat. no. WL01637; 1:500; Shenyang Wan Biotechnology Co., Ltd.), anti-cleaved-caspase-3 (cat. no. WL01992; 1:500; Shenyang Wan Biotechnology Co., Ltd.), anti-PTEN (cat. no. WL01901; 1:500; Shenyang Wan Biotechnology Co., Ltd.), anti-PI3K (cat. no. WL01169; 1:500; Shenyang Wan Biotechnology Co., Ltd.), anti-phosphorylated (p-) PI3K (cat. no. ab182651; 1:1,000; Abcam), anti-AKT (cat. no. WLP001a; 1:500; Shenyang Wan Biotechnology Co., Ltd.), anti-p-AKT (cat. no. WL0003b; 1:1,000; Shenyang Wan Biotechnology Co., Ltd.) and anti- $\beta$-actin (cat. no. WL01845; 1:1,000; Shenyang Wan Biotechnology Co., Ltd.). The following day, the PVDF membranes were incubated with horseradish peroxidase-labeled goat anti-rabbit immunoglobulin G secondary antibodies (cat. no. WLA023; 1:5,000; Shenyang Wan Biotechnology Co., Ltd.) at $37^{\circ} \mathrm{C}$ for $45 \mathrm{~min}$. Detection of the protein bands was performed using an enhanced chemiluminescence for western blotting kit 
(Shenyang Wan Biotechnology Co., Ltd.), according to the manufacturer's protocol. The levels of phosphorylated proteins were normalized to their corresponding total protein levels. Relative densitometry was calculated using Image $\mathrm{J} 2 \mathrm{x}$ analysis software (National Institutes of Health).

Reverse transcription-quantitative PCR (RT-qPCR). Total RNA was extracted from the myocardium and cardiomyocytes using TRIzol ${ }^{\circledR}$ reagent (Life Technologies; Thermo Fisher Scientific, Inc.) at $48 \mathrm{~h}$ after transfection. Subsequent to detecting the quality of the total RNA, RNA was reverse transcribed into cDNA using the PrimeScript RT reagent kit with gDNA Eraser (Takara Bio, Inc.), according to the manufacturer's protocol. The RNA was heated at $37^{\circ} \mathrm{C}$ for $15 \mathrm{~min}$ and at $85^{\circ} \mathrm{C}$ for $5 \mathrm{sec}$, and then cooled to $4^{\circ} \mathrm{C}$ to obtain the cDNA. RT-qPCR was then performed using SYBR Premix Ex Taq II (Takara Bio, Inc.), according to the manufacturer's protocol. The cDNA was amplified under the following thermocycling conditions: $95^{\circ} \mathrm{C}$ for $5 \mathrm{~min}$, followed by 8 cycles of $95^{\circ} \mathrm{C}$ for $30 \mathrm{sec}, 60^{\circ} \mathrm{C}$ for $45 \mathrm{sec}$ and $72^{\circ} \mathrm{C}$ for $20 \mathrm{sec}$; and 35 cycles of $95^{\circ} \mathrm{C}$ for $30 \mathrm{sec}, 56^{\circ} \mathrm{C}$ for $45 \mathrm{sec}, 72^{\circ} \mathrm{C}$ for $20 \mathrm{sec}, 95^{\circ} \mathrm{C}$ for $1 \mathrm{~min}, 55^{\circ} \mathrm{C}$ for $30 \mathrm{sec}$ and $95^{\circ} \mathrm{C}$ for $30 \mathrm{sec}$. For miRNA RT-qPCR, RNA was reverse transcribed into cDNA using the Super RT kit (Bioteke Biotechnology Co., Ltd.) according to the manufacturer's protocol. The RNA was heated at $37^{\circ} \mathrm{C}$ for $30 \mathrm{~min}$ and at $42^{\circ}$ or $30 \mathrm{~min}$, and then $70^{\circ} \mathrm{C}$ for $10 \mathrm{~min}$ to obtain the cDNA. RT-qPCR was then performed using SYBR Taq PCR MasterMix (Bioteke Biotechnology Co., Ltd.) according to the manufacturer's protocol. The cDNA was amplified under the following thermocycling conditions: $94^{\circ} \mathrm{C}$ for $2 \mathrm{~min}$, followed by $94^{\circ} \mathrm{C}$ for $15 \mathrm{sec}, 60^{\circ} \mathrm{C}$ for $15 \mathrm{sec}$ and $72^{\circ} \mathrm{C}$ for $15 \mathrm{sec} ; 40$ cycles of $72^{\circ} \mathrm{C}$ for $2 \mathrm{~min} 30 \mathrm{sec}$ and $40^{\circ} \mathrm{C}$ for $1 \mathrm{~min}$ $30 \mathrm{sec}$; melting from $60^{\circ} \mathrm{C}$ to $94^{\circ} \mathrm{C}$, with $1.0^{\circ} \mathrm{C}$ every $1 \mathrm{sec}$; and $25^{\circ} \mathrm{C}$ for $1 \mathrm{~min}$. All oligonucleotide primer pairs and the reference primers ( $\beta$-actin and U6) were designed by Sangon Biotech Co., Ltd. Relative gene expression was analyzed using the $2^{-\Delta \Delta \mathrm{Cq}}$ method (32). The primer sequences in the present study are presented in Table I.

Statistical analysis. The experimental data are expressed as the mean \pm standard deviation and were statistically analyzed using SPSS 23.0 software (SPSS, Inc.). Differences between the control and HR groups were evaluated using an independent sample Student's t-test. Differences between multiple groups were initially evaluated using a one-way analysis of variance followed by Bonferroni's test was performed to assess the comparisons between each two groups. $\mathrm{P}<0.05$ was considered to indicate a statistically significant difference. GraphPad Prism 5.0 software (GraphPad Software, Inc.) was used to draw the diagrams.

\section{Results}

LncRNA GAS5 expression is significantly upregulated following ischemia/reperfusion myocardial injury. In the present study, H9c2 cells treated with HR were used to simulate ischemia-reperfusion injury. The change in the expression levels of lncRNA GAS5 were detected between normally-cultured cells and HR-induced cells by RT-qPCR. It was revealed that 1 ncRNA GAS5 was significantly
Table I. Primer sequences in the present study.

Gene Primer sequence $\left(5^{\prime}-3^{\prime}\right)$

IncRNA-GAS5 forward lncRNA-GAS5 reverse miR-532-5p forward miR-532-5p reverse PTEN forward PTEN reverse

TCTCACAGGCAGTTCTGTGG
ATCCATCCAGTCACCTCTGG
CGCCCCATGCCTTGAGTGTA
GTGCAGGGTCCGAGGTATTC
TAGAGCGTGCGGATAATGAC
GATGGCTCCTCTACTGTTTT

lncRNA, long non-coding RNA; GAS5, growth arrest specific 5; miR, microRNA; PTEN, phosphatase and tensin homolog.

upregulated following HR compared with the normal control cells $(\mathrm{P}<0.05)$. The data indicated that the expression levels of 1ncRNA GAS5 were increased by twelve times in the HR group compared with the normal cell group (Fig. 1A). Then, 10 pairs of normal myocardial tissues and myocardial tissues subjected to ischemia-reperfusion injury from male SPF Wistar rats were collected. RNA was extracted from 10 groups of myocardial tissues and the expression of lncRNA GAS5 was measured using RT-qPCR. Similarly, the aforementioned conclusions were also confirmed in the myocardial tissues of rats with ischemia-reperfusion injury $(\mathrm{P}<0.01$; Fig. 1B). The present study reviewed the results of studies using lncRNAs that have been reported to be associated with myocardial ischemia-reperfusion injury. It has been reported that metastasis associated lung adenocarcinoma transcript 1 is upregulated $\sim$-fold in the context of ischemia-reperfusion mediation. Subsequent to intervention, significant positive results were revealed in subsequent functional tests (33). In addition, the data revealed that the expression levels of lncRNA-regulator of reprogramming was significantly increased by nearly 2 -fold compared with the control group in the ischemia-reperfusion injury group (34). Therefore, the upregulation of IncRNA is notable. The present results suggest that lncRNA GAS5 may serve an important function in the process of MIRI.

Silencing of IncRNA GAS5 may protect H9c2 cells against $H R$ injury in $H 9 c 2$ cells. The present study further investigated the functional effects of lncRNA GAS5 in the HR model by altering the expression of IncRNA GAS5. siRNA was transfected to successfully silence the expression of lncRNA GAS5, as presented in Fig. 2A. The silencing efficiency of the siRNA sequences was $\sim 80 \%$. The experimental group with transfection reagent alone was used to confirm that the transfection reagent had no significant additional damaging effect on the cells. Cell viability was tested using a CCK- 8 assay. The data revealed that subsequent to silencing the highly expressed lncRNA GAS5, the cell viability was restored significantly, and the cell damage caused by $\mathrm{HR}$ was alleviated $(\mathrm{P}<0.05$; Fig. 2B). Furthermore, the detection of changes in the levels of myocardial necrosis markers, including $\mathrm{LDH}$ and $\mathrm{CK}-\mathrm{MB}$, was performed. It was revealed that the silencing of IncRNA GAS5 significantly reduced myocardial enzyme release $(\mathrm{P}<0.01)$. This further proved 
A

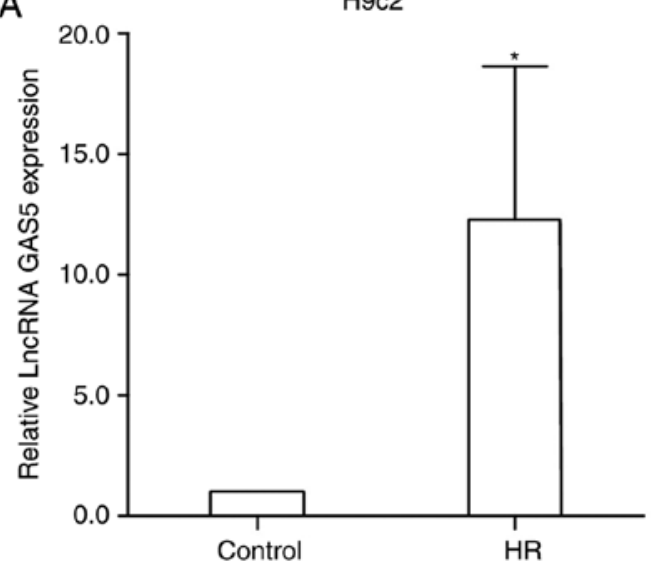

B

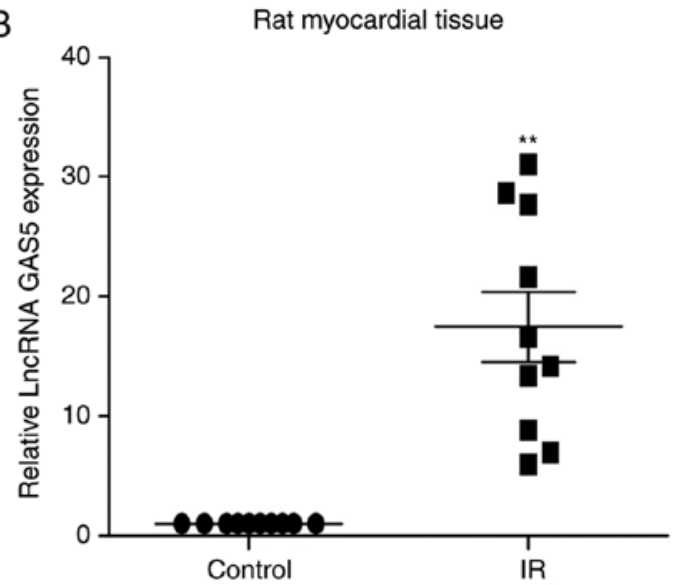

Figure 1. LncRNA GAS5 is highly expressed in myocardial hypoxia-reoxygenation and ischemia-reperfusion. (A) Expression levels of lncRNA GAS5 in HR-induced H9c2 cells were detected using RT-qPCR. $n=3,{ }^{*} \mathrm{P}<0.05$ vs. the control. (B) Expression levels of lncRNA GAS5 in IR-induced myocardia tissue were detected using RT-qPCR. $\mathrm{n}=10,{ }^{* *} \mathrm{P}<0.01$ vs. the control. Data are presented as the mean \pm standard deviation. IR, ischemia-reperfusion; HR, hypoxia-reoxygenation; lncRNA, long non-coding RNA; GAS5, growth arrest specific 5; RT-qPCR, reverse transcription-quantitative PCR.
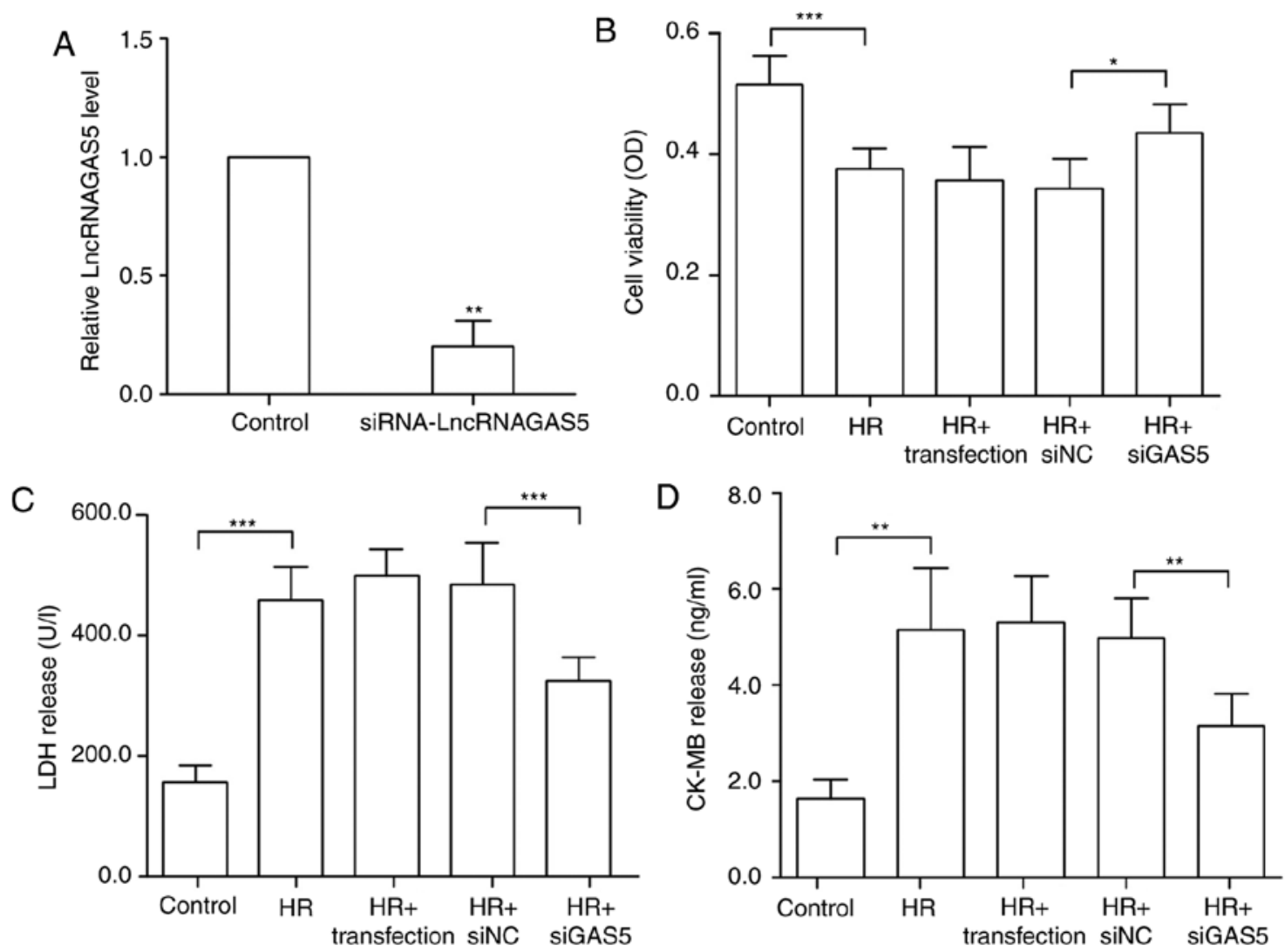

Figure 2. Silencing of lncRNA GAS5 is able to protect H9c2 cells against HR injury. (A) H9c2 cells were transfected using siGAS5, and it was verified that the silencing efficiency reached $80 \%{ }^{* *} \mathrm{P}<0.01$ vs. the control. (B) Silencing of lncRNA GAS5 significantly improves cell viability as demonstrated by Cell Counting Kit 8 assays. (C) Release levels of LDH. (D) Release levels of CK-MB. ${ }^{*} \mathrm{P}<0.05,{ }^{* *} \mathrm{P}<0.01$ and ${ }^{* * * *} \mathrm{P}<0.001$ with comparisons shown by lines. $\mathrm{n}=3$. Data are presented as the mean \pm standard deviation. Control, cells with a normal culture; HR, cells with hypoxia/reoxygenation injury treatment; HR+transfection, cells with hypoxia/reoxygenation injury and transfection reagent only; HR+siNC, cells with hypoxia/reoxygenation injury and negative control transfection; HR+siGAS5, cells with hypoxia/reoxygenation injury and siRNA-GAS5 transfection; lncRNA, long non-coding RNA; GAS5, growth arrest specific 5; si/siRNA, small interfering RNA; NC, negative control; HR, hypoxia-reoxygenation; LDH, lactate dehydrogenase; CK-MB, creatine kinase isoenzyme; OD, optical density.

that the degree of cell damage was reduced (Fig. 2C and D). Therefore, the present study preliminarily demonstrated that the silencing of lncRNA GAS5 may alleviate myocardial HR damage.
Targeted regulation of IncRNA GAS5 is able to attenuate apoptosis induced by myocardial HR injury in H9c2 cells. To investigate the regulatory function of lncRNA GAS5 in myocardial HR injury, the present study further examined the 
regulation of apoptosis. The cells were first stained via Hoechst staining, and apoptotic changes were visually observed with the naked eye. Under a fluorescence microscope, the living cells were diffusely and uniformly fluorescent, and a dense agglomerated granular block fluorescence was observed in the apoptotic cell nucleus or cytoplasm. As presented in Fig. 3A, the blue mass was the nucleus; once apoptosis occurred, blue clumps were observed, the chromatin shrank and highlighting occurred. It was revealed that the number of apoptotic cells induced by HR was reduced following the silencing of lncRNA GAS5. The apoptosis rate was expressed by calculating the apoptotic cells and the total number of cells in the same visual field with the naked eye. The results of the experiment preliminarily demonstrated that lncRNA GAS5 is involved in the regulation of apoptosis in myocardial HR injury. Then, flow cytometry was used to further analyze cell apoptosis in the HR model. The early and late apoptotic rates of cells were compared prior to and following the silencing of 1ncRNA GAS5. The results indicated that the silencing of lncRNA GAS5 significantly reduced the apoptotic rates of the cells $(\mathrm{P}<0.01$; Fig. 3B). As a result of the previous experiments, it was demonstrated that lncRNA GAS5 serves a function in regulating apoptosis in cardiomyocytes. Next, the expression of major apoptosis-associated proteins was assessed during myocardial ischemia-reperfusion, including the anti-apoptotic factors $\mathrm{Bcl} 2$ and $\mathrm{Bax}$, in addition to the pro-apoptotic factor caspase-3. The results revealed that the protein expression levels of $\mathrm{Bcl} 2$ were significantly downregulated following HR treatment $(\mathrm{P}<0.001)$, while the protein expression level of Bax was significantly upregulated $(\mathrm{P}<0.001)$, and the ratio of $\mathrm{Bcl} 2 / \mathrm{Bax}$ decreased. Protein expression exhibited a trend towards recovery subsequent to the silencing of lncRNA GAS5 (Fig. 3C-G). Caspase-3 is a pro-apoptotic protein downstream of the apoptotic pathway. It was revealed that there was the significantly upregulated expression of caspase-3 following HR treatment compared with the control $(\mathrm{P}<0.001)$, but the expression levels significantly decreased following the silencing of the expression of lncRNA GAS5 ( $\mathrm{P}<0.01$; Fig. $3 \mathrm{H}$ and I). The results suggested that lncRNA GAS5 may serve a function in MIRI by participating in the regulation of apoptosis.

lncRNA GAS5 functions as a molecular sponge for miR-532-5p in H9c2 cells. In order to clarify the downstream regulation of lncRNA GAS5, previous studies were assessed, and it was revealed that it is able to function as a competing endogenous (ceRNA) to regulate apoptosis $(35,36)$. To further investigate the regulatory mechanisms of 1ncRNA GAS5 in MIRI, bioinformatics analysis was used to predict target genes. miRNAs that may have binding sites for lncRNA GAS5 were identified via predictive software (RNAhybrid online) (37). Through screening, the present study focused on miR-532-5p, which had the highest score. The binding site of miR-532-5p in the lncRNA GAS5 sequence was obtained by using bioinformatics analysis (Fig. 4A). Following that, the expression of miR-532-5p in a model of myocardial HR was detected by RT-qPCR. It was revealed that the expression of miR-532-5p was significantly downregulated under HR treatment compared with the control $(\mathrm{P}<0.001)$, contrary to lncRNA GAS5 expression. Furthermore, miR-532-5p was significantly upregulated in response to lncRNA GAS5 silencing $(\mathrm{P}<0.001$;
Fig. 4B). From another perspective, the expression of lncRNA GAS5 following the silencing of miR-532-5p was assessed by RT-qPCR. miRNA mimic and inhibitor were used to perform miRNA overexpression and silencing, respectively. The transfection efficiency is presented in Fig. 4C and D. The results were consistent with the predictions; when the expression of miR-532-5p was altered, IncRNA GAS5 also exhibited significant corresponding expression changes $(\mathrm{P}<0.01$; Fig. $4 \mathrm{E})$. The results further illustrated that miR-532-5p and lncRNA GAS5 may combine and serve a function in myocardial HR injury. To validate the accuracy of the targets predicted by bioinformatics analysis, luciferase reporter assays were performed to further investigate the combination of 1ncRNA GAS5 and miR-532-5p. The luciferase activity of GAS5-WT was significantly reduced by miR-532-5p mimics $(\mathrm{P}<0.01)$. However, the luciferase activity of GAS5-MUT was not significantly altered (Fig. 4F). These results confirmed that miR-532-5p is a target of 1ncRNA GAS5 and that lncRNA GAS5 may function as a ceRNA in HR-induced apoptosis.

miR-532-5p serves a function in HR injury in $\mathrm{H} 9 \mathrm{c} 2$ cells. Ma et al (38) reported that miR-532-5p may alleviate hypoxia-induced cardiomyocyte apoptosis. To further confirm whether miR-532-5p serves a function in myocardial HR, the present study investigated the biological functions of miR-532-5p in H9c2 cells by gain- and loss-of-function analyses. miRNA mimic and miRNA inhibitor were transfected into $\mathrm{H} 9 \mathrm{c} 2$ cells to overexpress and inhibit the expression of miR-532-5p, respectively. The aforementioned cellular HR model was established. Similarly, cell viability and myocardial enzyme indexes were analyzed. The results of the CCK-8 assay revealed that when the miRNA mimic was transfected, the original decreased cell viability was significantly reversed $(\mathrm{P}<0.01)$. Conversely, inhibition significantly reduced cell viability $(\mathrm{P}<0.05$; Fig. $5 \mathrm{~A})$. In terms of myocardial enzymology, the results for CK-MB (Fig. 5B) and LDH (Fig. 5C) were similar, further demonstrating that overexpression may alleviate the damage to some extent, and that inhibition may aggravate the damage.

Alterations in miR-532-5p expression may regulate the degree of apoptosis induced by $\mathrm{HR}$ in $\mathrm{H} 9 \mathrm{c} 2$ cells. A flow cytometry was used to initially detect the effects on cell apoptosis. The early and late apoptotic rates of cells were compared prior and subsequent to altering the expression of miR-532-5p. The results suggested that the overexpression of miR-532-5p significantly suppressed cell apoptosis, while the inhibition of miR-532-5p significantly aggravated cell apoptosis $(\mathrm{P}<0.001$; Fig. 6A). The changes at the protein level further revealed the effect of miR-532-5p on cell apoptosis. The expression of classical apoptotic proteins was examined by western blotting. The expression trends of Bcl-2 (Fig. 6B and D), Bax (Fig. 6C and E) and caspase-3 (Fig. 6G and $\mathrm{H}$ ) were consistent with the predictions. The expression of the pro-apoptotic proteins, which were notably induced by injury, were significantly decreased under the action of the miRNA mimic and overexpressed under the action of the miRNA inhibitor $(\mathrm{P}<0.05)$. However, the anti-apoptotic proteins exhibited the opposite trend. Further analysis of the ratio of Bcl-2 to Bax indicated that the effect of the miRNA mimic was more substantial compared 


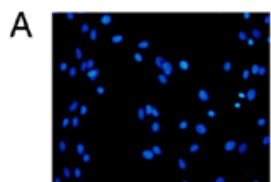

Control

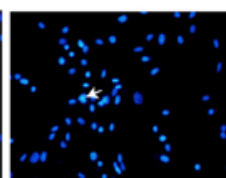

HR

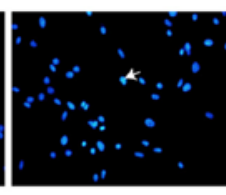

$\mathrm{HR}+$ transfection

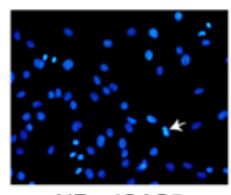

HR+siGAS5
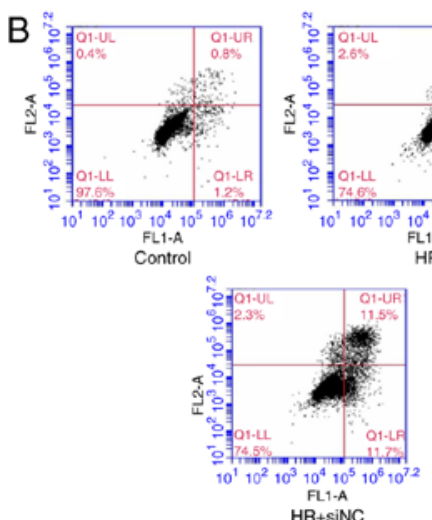

$\mathrm{HR}+\mathrm{siNC}$

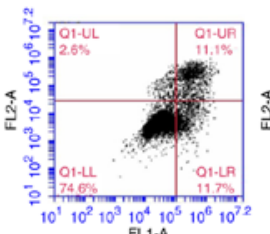

FL1-A

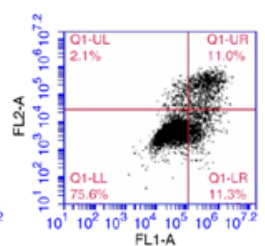

$M R$ transfection

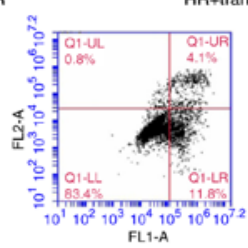

FL1-A
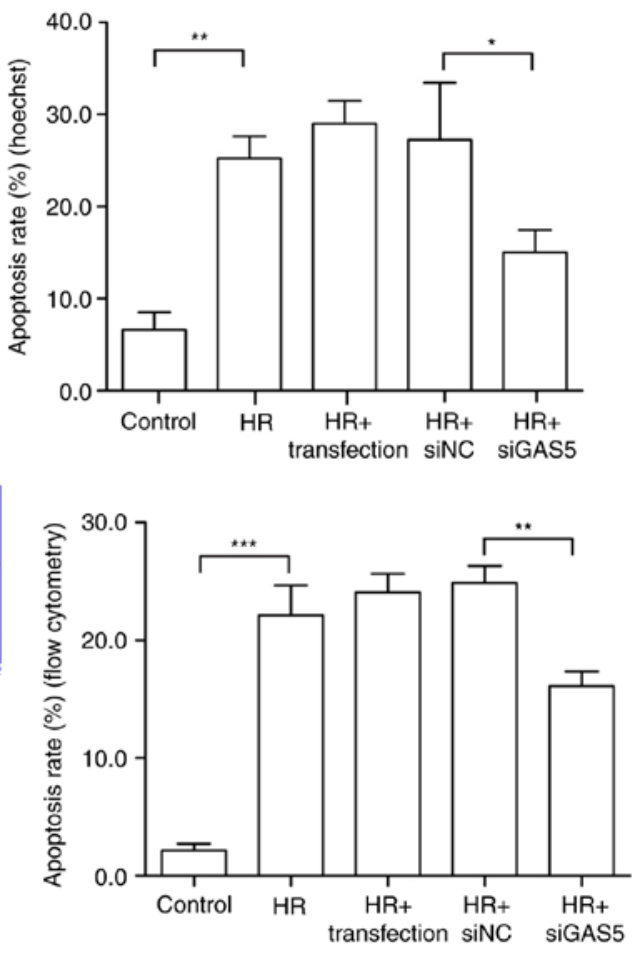

C
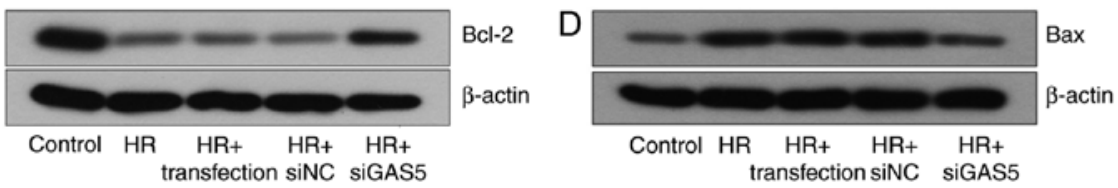

$E$
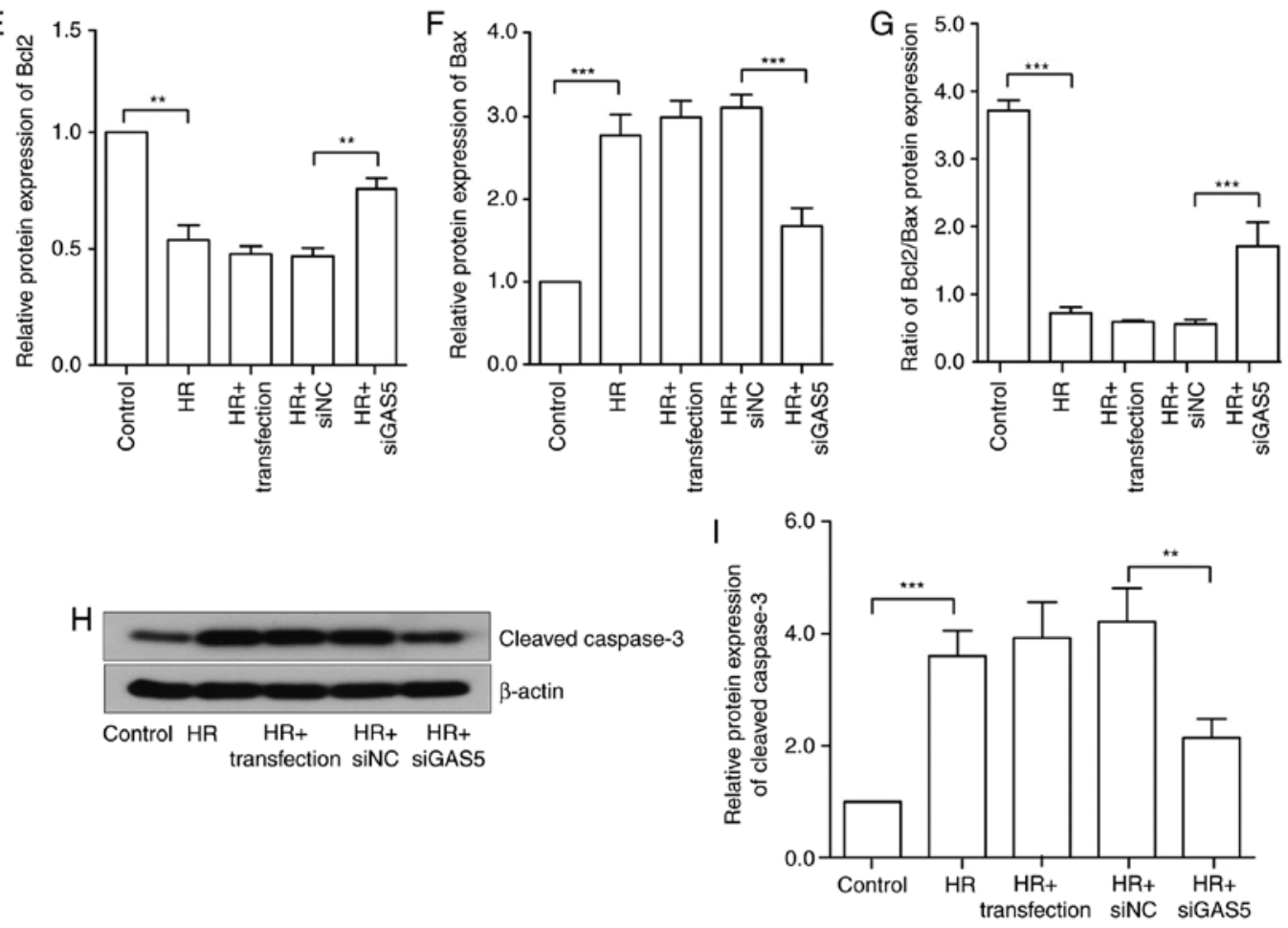

Figure 3. LncRNA GAS5 alleviates the apoptosis caused by hypoxia/reoxygenation. (A) Evaluation of apoptotic cells by Hoechst staining. Left panel: The nucleus of apoptotic cells is densely stained; the arrow points to apoptotic cells. Right panel: Quantified apoptosis rate. (B) Left panel: Evaluation of apoptotic cells by flow cytometry. Right panel: Quantified early apoptosis rate and late apoptosis rates. (C) Protein expression of Bcl2 in H9c2 cells detected by western blotting. (D) Protein expression of Bax in H9c2 cells detected by western blotting. (E) Quantitative value of relative protein expression levels of Bcl-2. (F) Quantitative value of relative protein expression levels of Bax. (G) Ratio of protein expression of Bcl-2/Bax in H9c2 cells. (H) Protein expression of cleaved caspase 3 in $\mathrm{H} 9 \mathrm{c} 2$ cells detected by western blotting. (I) Quantitative value of relative protein expression levels of cleaved caspase 3 . * $\mathrm{P}<0.05$, ${ }^{* *} \mathrm{P}<0.01$ and ${ }^{*}{ }^{* *} \mathrm{P}<0.001$ with comparisons shown by lines. Data are presented as the mean \pm standard deviation; n=3. LncRNA, long non-coding RNA; GAS5, growth arrest specific 5; si/siRNA, small interfering RNA; NC, negative control; HR, hypoxia-reoxygenation; Bax, Bcl-2-associated X protein; Bcl2, B-cell lymphoma 2. 


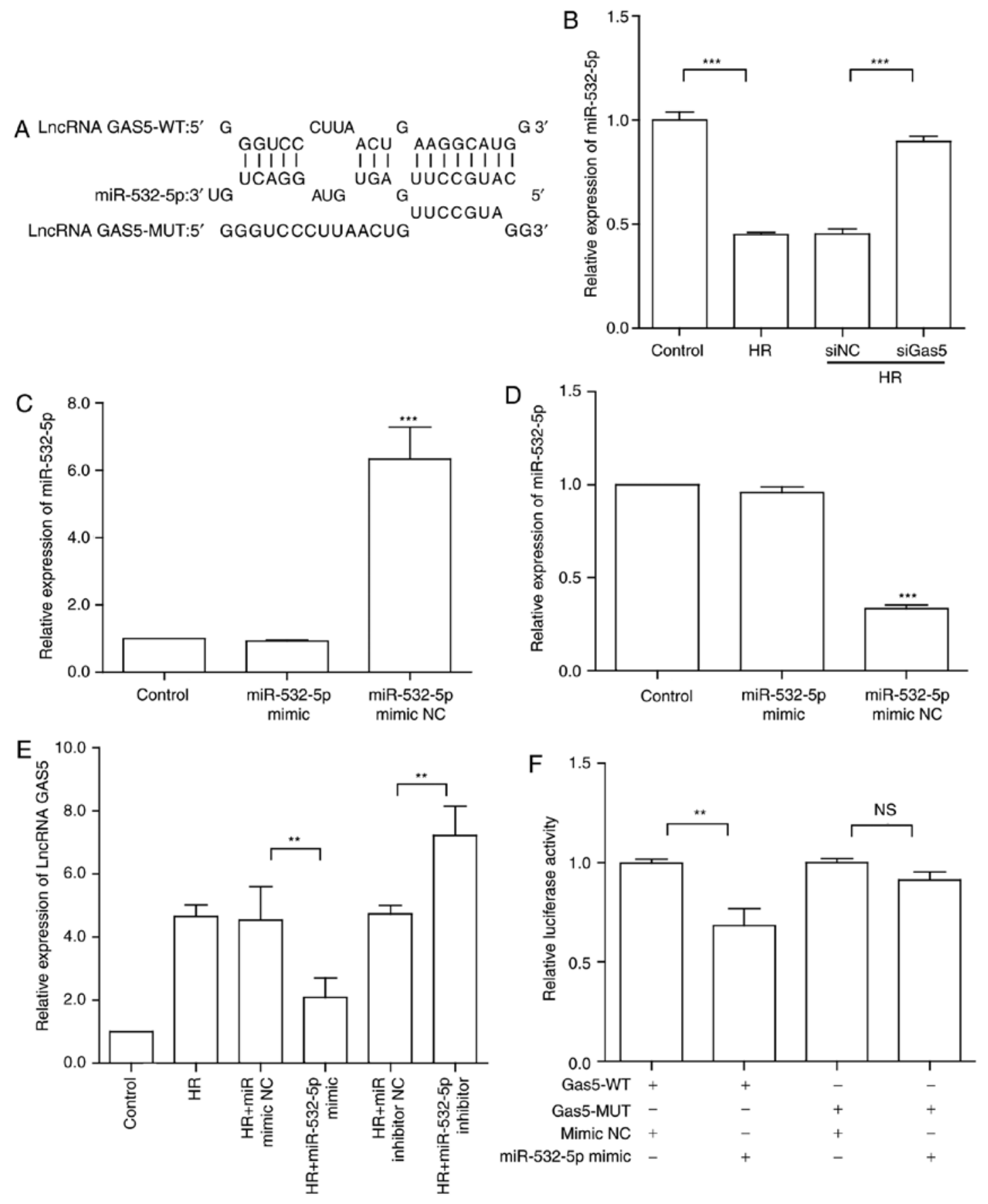

Figure 4. LncRNA GAS5 functions as a molecular sponge for miR-532-5p in H9c2 cells. (A) Prediction of miR-532-5p binding sites on the lncRNA GAS5 transcript and the Luciferase assay mutated sequence. (B) Expression levels of miR-532-5p were detected under HR treatment and the simultaneous inhibition of IncRNA GAS5 by PCR. (C) Transfection efficiency of miR-532-5p mimic. ${ }^{* * *} \mathrm{P}<0.001$ vs. the control. (D) Transfection efficiency of miR-532-5p inhibitor. ${ }^{* * * *} \mathrm{P}<0.001$ vs. the control. (E) Expression levels of IncRNA GAS5 were detected following the intervention of miR-532-5p with HR treatment by PCR. (F) Combination between lncRNA GAS5 and miR-532-5p was demonstrated using a luciferase reporter assay. ${ }^{* *} \mathrm{P}<0.01$ and ${ }^{* * * *} \mathrm{P}<0.001$ with comparisons shown by lines. Data are presented as the mean \pm standard deviation. $n=3$. LncRNA, long non-coding RNA; GAS5, growth arrest specific 5; miR, microRNA; HR, hypoxia-reoxygenation; NC, negative control; WT, wild type; MUT, mutant.

with that of the miRNA inhibitor; the results were not statistically significant $(\mathrm{P}>0.05)$, but a certain trend was observed (Fig. 6F). These results confirmed the hypothesis that IncRNA GAS5 may function in HR-induced apoptosis by binding to miR-532-5p to regulate target gene expression.

IncRNA GAS5 regulates PTEN through miR-532-5p in HR injury. The PI3K/AKT signaling pathway is an important pathway in the regulation of apoptosis, and it has also been reported to serve an important anti-apoptotic function in MIRI (9). Firstly, it was revealed that in the $\mathrm{H} 9 \mathrm{c} 2$ cells subjected to HR, PTEN was also significantly upregulated compared with the control $(\mathrm{P}<0.01)$, consistent with the trend of lncRNA GAS5 expression. Subsequent to further intervention with siGAS5, PTEN also exhibited a significant decrease $(\mathrm{P}<0.05$; Fig. 7A), and protein expression was also reduced $(\mathrm{P}<0.05$; Fig. $7 \mathrm{C}$ and $\mathrm{D})$. Bioinformatics analysis was used to predict target binding sites between miR-532-5p and PTEN. It was revealed using the 

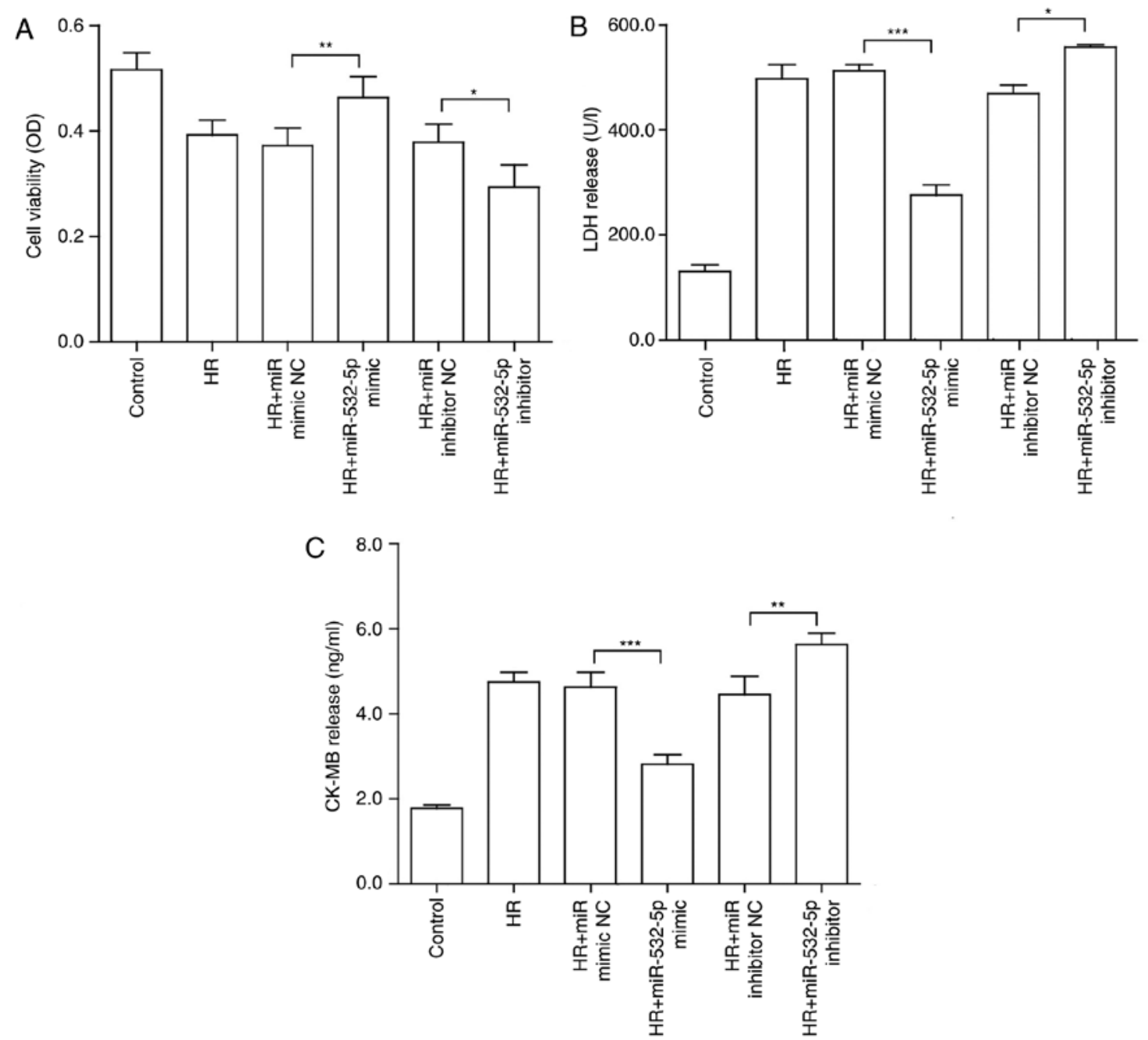

Figure 5. miR-532-5p serves a function in hypoxia-reoxygenation injury in H9c2 cells. (A) Cell viability of H9c2 cells transfected with miR-532-5p mimic or inhibitor detected by a Cell Counting Kit 8 assay. (B) Release levels of LDH. (C) Release levels of CK-MB. ${ }^{*} \mathrm{P}<0.05,{ }^{* * *} \mathrm{P}<0.01$ and ${ }^{* * * *} \mathrm{P}<0.001$ with comparisons shown by lines. Data are presented as the mean \pm standard deviation. $n=3$. miR, microRNA; HR, hypoxia-reoxygenation; NC, negative control; LDH, lactate dehydrogenase; CK-MB, creatine kinase isoenzyme; OD, optical density.

TargetScan online database that they have potential binding sites (Fig. 7G) (39). In addition, the same trend was observed following the alteration of miR-532-5p alone. With the change in miR-532-5p expression, the gene expression levels of PTEN also changed accordingly ( $\mathrm{P}<0.05$; Fig. 7B). Protein expression was consistent with the trend in gene expression (Fig. 7E and F). The results suggested that PTEN may be a target gene for miR-532-5p, and that lncRNA GAS5 regulated PTEN expression by binding to miR-532-5p. Then, a luciferase reporter assay was performed to verify the predicted results. The data in Fig. $7 \mathrm{H}$ revealed that the relative luciferase activity was significantly inhibited by co-transfection using PTEN-WT and miR-532-5p mimics, when compared with co-transfection with PTEN-WT and miR-NC $(\mathrm{P}<0.05)$. The luciferase activity of PTEN-MUT was almost unchanged. The aforementioned results suggested that PTEN is a target gene of miR-532-5p and that lncRNA GAS5 may regulate PTEN through miR-532-5p in HR injury.

IncRNA GAS5 modulates the PI3K/AKT signaling pathway in HR injury. Based on previous experimental results and the conclusion of the bioinformatics analysis, a hypothesis was proposed: IncRNA GAS5 targets PTEN by binding to
miR-532-5p, thereby inhibiting the activation of the PI3K/AKT pathway. In order to further confirm the regulatory mechanism of the IncRNA GAS5/miR-532-5p/PTEN axis in HR-induced apoptosis, a rescue experiment was designed. The expression of PTEN was upregulated during the HR of cardiomyocytes, and decreased following lncRNA GAS5 inhibition. In the next experiment, H9c2 cells were transfected with siGAS5 and miR-532-5p inhibitor, individually and together, and then treated with HR. Transfection of siGAS5 alone reduced the gene expression of PTEN. When the cells were simultaneously transfected with miR-532-5p inhibitor, the downregulation of PTEN was significantly reversed $(\mathrm{P}<0.05$; Fig. $8 \mathrm{~A})$. Regarding the protein expression of PTEN, the results were consistent with the RT-qPCR results ( $\mathrm{P}<0.05 ;$ Fig. 8B). Following the same test groups, the upstream and downstream molecules involved in the action of PTEN were examined. The expression of proteins including PI3K, AKT and their phosphorylated forms was assessed using western blotting. The protein expression results of PI3K and p-PI3K are presented in Fig. 8C and D. The protein expression results of AKT and p-AKT are presented in Fig. 8E and F. The results indicated that silencing lncRNA GAS5 activated the PI3K/AKT pathway, which may be inhibited 

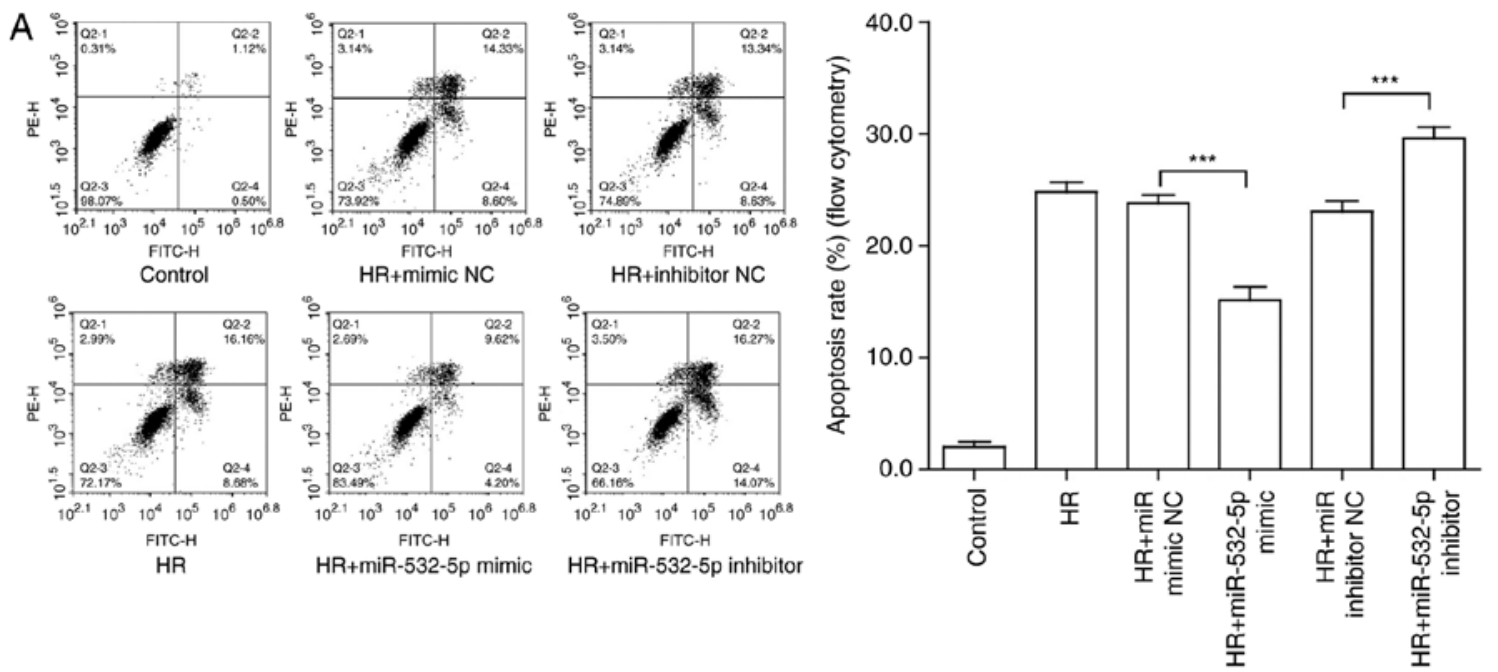

$\mathrm{B}$
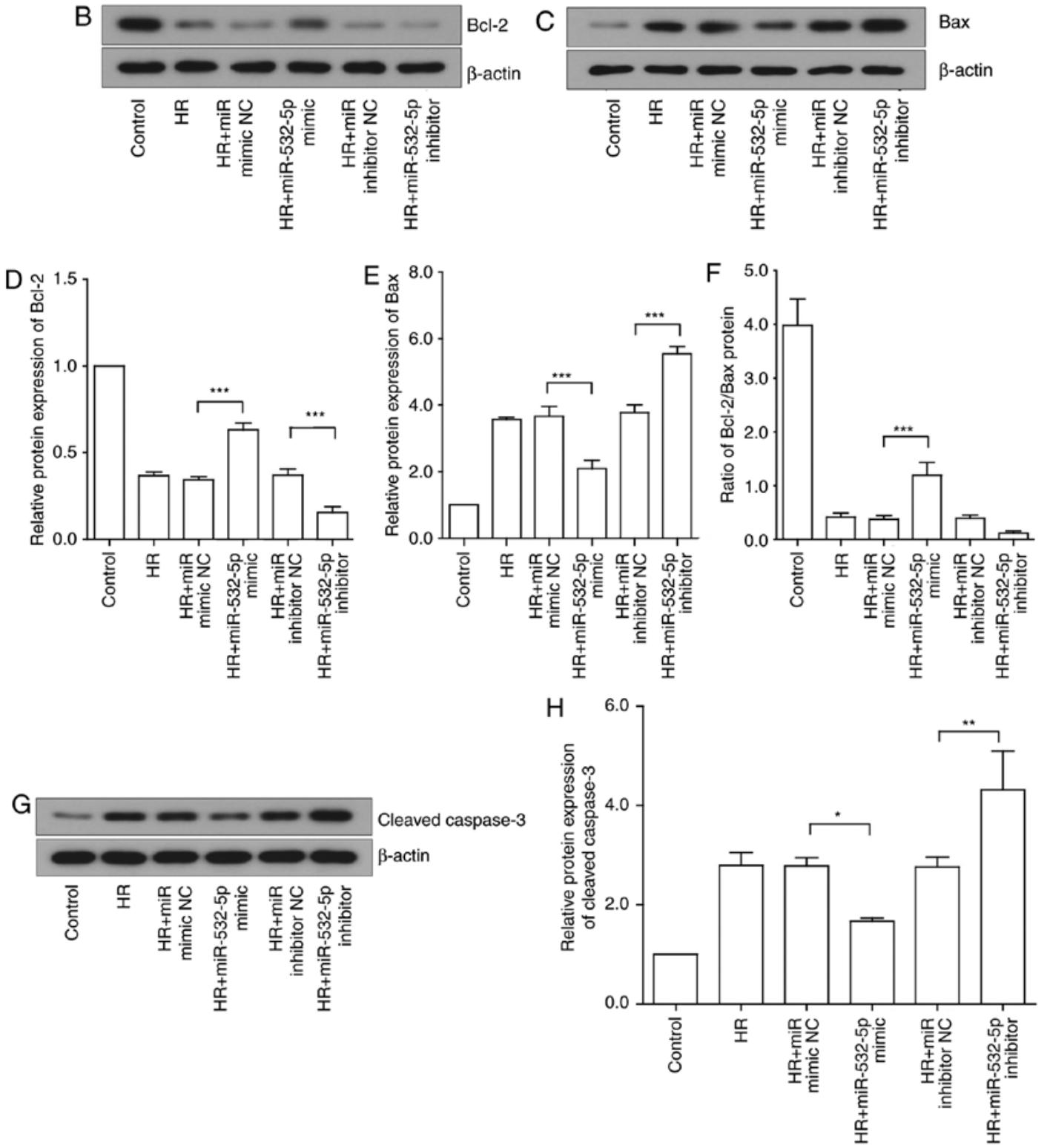

Figure 6. Intervention of miR-532-5p expression may regulate the degree of apoptosis induced by HR in H9c2 cells. (A) Left panel: Evaluation of apoptotic cells by a flow cytometry assay. Right panel: Quantified early apoptosis rate and late apoptosis rates. (B) Protein expression of Bcl2 in H9c2 cells detected by western blotting. (C) Protein expression of Bax in H9c2 cells detected by western blotting. (D) Quantitative value of relative protein expression levels of Bcl2. (E) Quantitative value of relative protein expression levels of Bax. (F) Ratio of protein expression of Bcl2/Bax in H9c2 cells. (G) Protein expression of cleaved caspase 3 in $\mathrm{H} 9 \mathrm{c} 2$ cells detected by western blotting. (H) Quantitative value of relative protein expression levels of cleaved caspase 3 . ${ }^{*} \mathrm{P}<0.05,{ }^{* *} \mathrm{P}<0.01$ and ${ }^{* * *} \mathrm{P}<0.001$ with comparisons shown by lines. Data are presented as the mean \pm standard deviation. $\mathrm{n}=3$. miR, microRNA; HR, hypoxia-reoxygenation; Bax, Bcl-2-associated X protein; Bcl2, B-cell lymphoma 2; NC, negative control. 

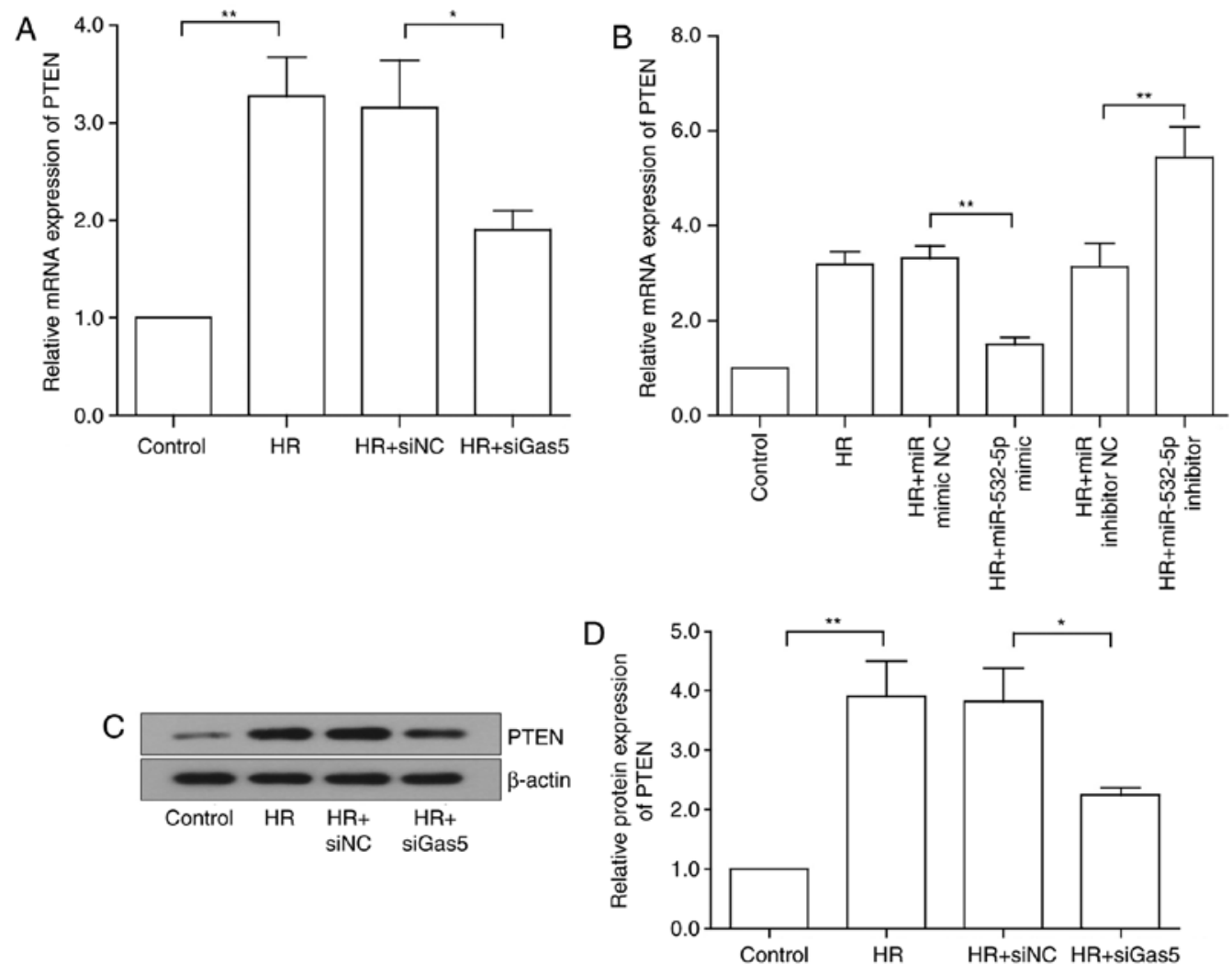

$\mathrm{E}$

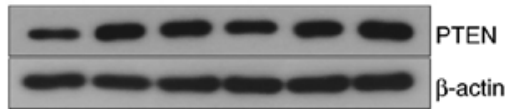

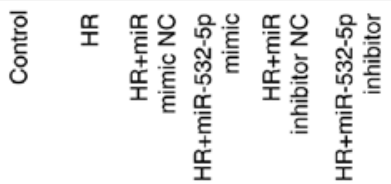

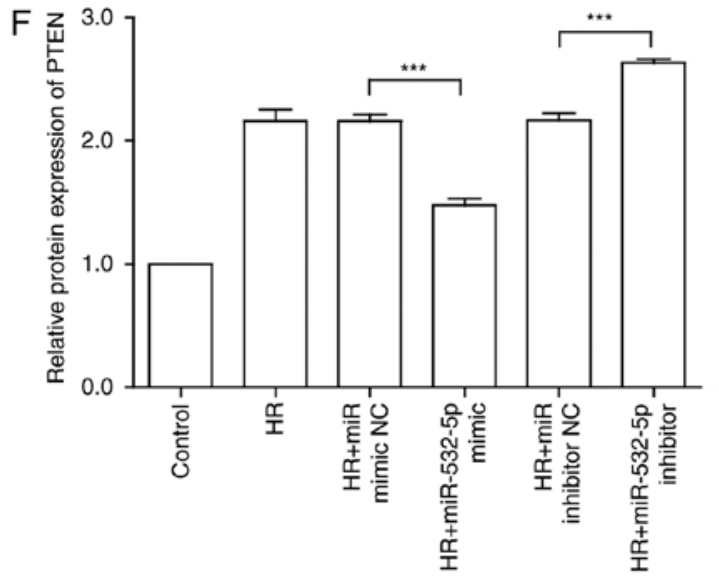

G Position 1352-1358 of PTEN 3' UTR PTEN-WT 5' ...CACUGCACGAaUAAU miR-532-5p 3' UGUCAGGAUGUGAG $\begin{array}{ccc}\text { AAGGCAU } \\ \text { II I I I I I I } \\ \text { UUCCGUA } \\ \text { PTEN-MUT 5' ...CACUGCACGAAUAAUUUCCGUAU...... } & 3^{\prime}\end{array}$

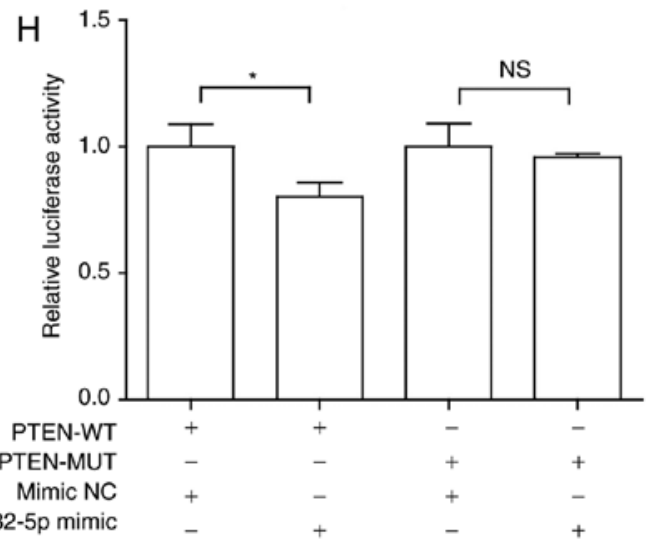

Figure 7. LncRNA GAS5 regulates PTEN through miR-532-5p in HR injury. (A) Gene expression of PTEN following lncRNA GAS5 intervention. (B) Gene expression of PTEN following miR-532-5p intervention. (C) Protein expression of PTEN following lncRNA GAS5 intervention. (D) Quantitative value of relative protein expression levels of PTEN. (E) Protein expression of PTEN following miR-532-5p intervention. (F) Quantitative value of relative protein expression levels of PTEN. (G) Prediction of miR-532-5p binding sites on the PTEN transcript. Luciferase assay mutated sequence. (H) Association between PTEN and miR-532-5p was demonstrated using a luciferase reporter assay. ${ }^{*} \mathrm{P}<0.05,{ }^{* *} \mathrm{P}<0.01$ and ${ }^{* * * *} \mathrm{P}<0.001$ with comparisons shown by lines. Data are presented as the mean \pm standard deviation. $\mathrm{n}=3$. LncRNA, long non-coding RNA; GAS5, growth arrest specific 5; PTEN, phosphatase and tensin homolog; miR, microRNA; HR, hypoxia-reoxygenation; si, small interfering RNA; NC, negative control; WT, wild type; MUT, mutant; 3'UTR, 3' untranslated region. 

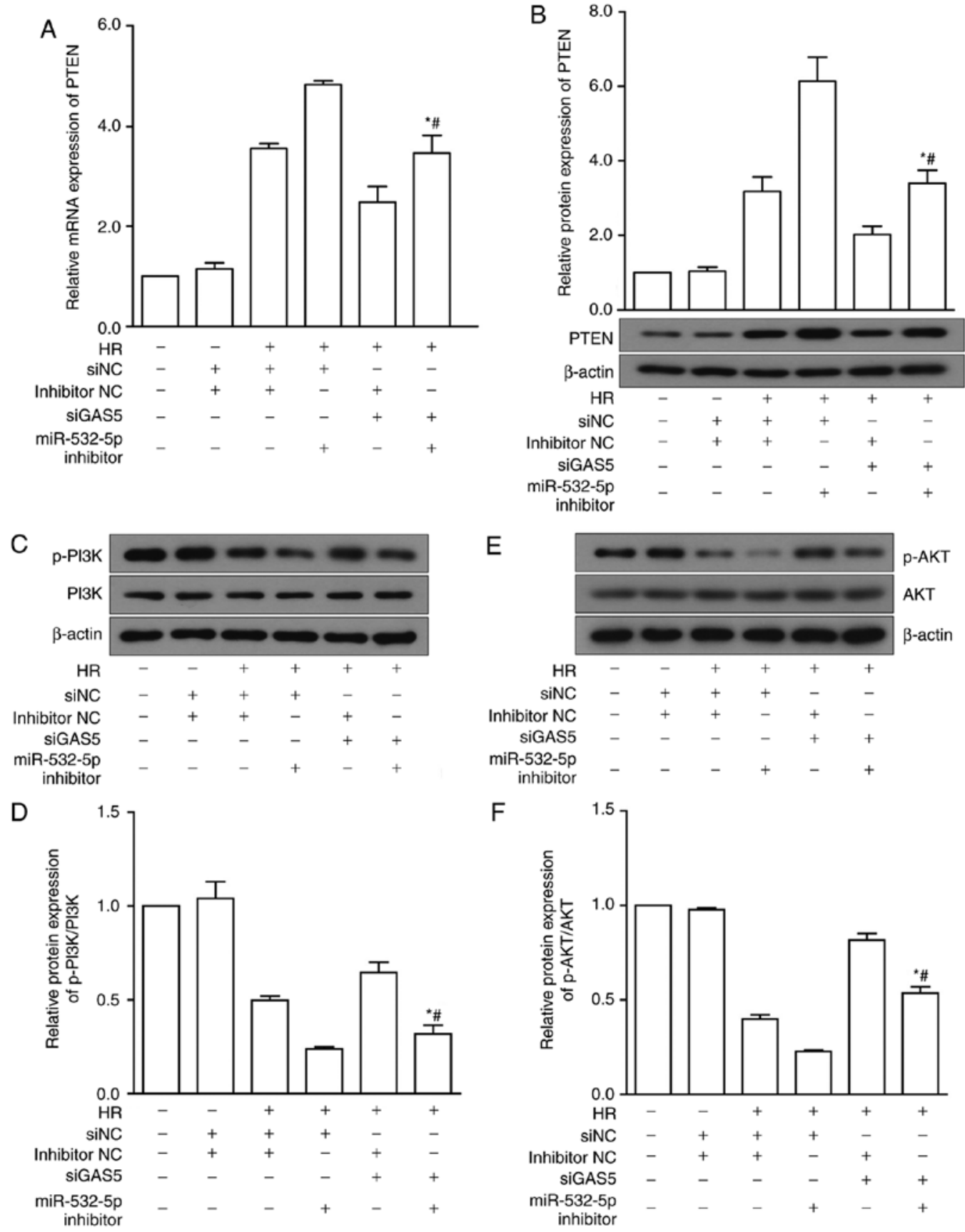

Figure 8. LncRNA GAS5 modulates the PI3K/AKT signaling pathway in HR injury. (A) Gene expression of PTEN under siGAS5 and miR-532-5p inhibitor alone and with co-intervention. (B) Protein expression levels of PTEN under siGAS5 and miR-532-5p inhibitor alone and with co-intervention. (C) Protein expression of PI3K and p-PI3K under siGAS5 and miR-532-5p inhibitor alone and with co-intervention. (D) Quantitative value of relative protein expression levels of p-PI3K/PI3K. (E) Protein expression of AKT and p-AKT under siGAS5 and miR-532-5p inhibitor alone and with co-intervention. (F) Quantitative value of relative protein expression levels of $\mathrm{p}-\mathrm{AKT} / \mathrm{AKT}$. ${ }^{*} \mathrm{P}<0.05 \mathrm{vs}$. HR+siNC+miR-532-5p inhibitor. ${ }^{*} \mathrm{P}<0.05$ vs. HR+siGAS5+inhibitor NC. Data are presented as the mean \pm standard deviation. $n=3$. LncRNA, long non-coding RNA; GAS5, growth arrest specific 5; PI3K, phosphoinositide-3-kinase; AKT, protein kinase B; p-, phosphorylated; HR, hypoxia-reoxygenation; si, small interfering RNA; NC, negative control; PTEN, phosphatase and tensin homolog; miR, microRNA; NC, negative control.

by miR-532-5p inhibitor. Thus, it was preliminarily concluded that the silencing of IncRNA GAS5 promotes the activation of the PI3K/AKT signaling pathway, potentially by sponging miR-532-5p.

\section{Discussion}

Although the study of MIRI has a long history, researchers are still continually trying to investigate this phenomenon.
Apoptosis is the main cause of cell death caused by ischemia-reperfusion injury, which induces the activation of the apoptotic pathway $(40,41)$. The PI3K/AKT signaling pathway is a classical cell survival pathway that has been suggested to be involved in the regulation of apoptosis induced by MIRI, mainly via the promotion of cell survival $(9,42)$. The PI3K/AKT signaling pathway is regulated by a variety of factors. PTEN is a key enzyme, functioning as an inhibitor of the activity of AKT in this pathway, and thereby inhibiting 
downstream effector molecules. It also serves an important function in MIRI $(43,44)$. In previous years, an increasing number of studies focusing on the upstream regulatory factors of PTEN have revealed that certain lncRNAs and miRNAs may regulate their expression in a variety of ways. Ke et al (45) indicated that miR-93 may protect against HR-induced cardiomyocyte apoptosis by inhibiting the PI3K/AKT/PTEN signaling pathway. It has also been reported that lncRNAs may directly or indirectly regulate PTEN during apoptosis in tumor cells (46).

lncRNAs were previously thought to be transcriptional noise with no biological function. With continuous development in the life sciences, epigenetics and genomics, an increasing number of lncRNAs have been discovered and named, and their potential functions in the regulation of a variety of biological processes have been discovered simultaneously (47). Although lncRNAs themselves do not have protein-coding functions, they may indirectly exert biological effects by binding to miRNAs, protein-coding RNA or proteins, and the mechanism of action is very complicated (48). Tumors were an early focus of lncRNA research (49). Gradually, other lncRNAs have been revealed to serve a function in systemic diseases with biological processes similar to those of a tumor $(50,51)$. Due to their pathophysiological characteristics, certain lncRNAs have also been revealed in cardiovascular diseases. The lncRNA metastasis-associated lung adenocarcinoma transcript 1 has been reported to be involved in the regulation of apoptosis (33) and inflammatory responses (52) induced by MIRI.

Previous research established that lncRNA GAS5 is abundant in cells whose growth has been arrested due to a lack of nutrients or growth factors (23). The function of IncRNA GAS5 in the regulation of apoptosis was initially discovered in a functional cloning experiment, in which the researchers isolated a portion of the lncRNA GAS5 sequence that inhibits apoptosis from $\gamma$-irradiated mouse thymoma cells (53). Kino et al (23) revealed that IncRNA GAS5 may sensitize cells to apoptosis by suppressing the glucocorticoid-mediated induction of a number of responsive genes, including the one encoding the cellular inhibitor of apoptosis protein. In the past two decades, a number of researchers have reported that lncRNA GAS5 participates in the processes of proliferation, migration and invasion in numerous tumor types, including colorectal cancer, breast cancer, prostate cancer, non-small-cell lung cancer and thyroid cancer $(24,25,27,54)$. However, there is very little published research in the field of ischemic heart disease associated with IncRNA GAS5. One previous study on cardiovascular disease was on myocardial fibrosis. LncRNA GAS5 was revealed to be expressed at low levels in cardiac fibrosis tissues, in addition to activated cardiac fibroblasts. Overexpression of IncRNA GAS5 inhibited the proliferation of cardiac fibroblasts. It was further discovered that lncRNA GAS5 may regulate the expression of PTEN by binding to miRNA-21 to affect myocardial fibrosis (36).

As mentioned earlier, the process of ischemia-reperfusion may involve multiple mechanisms. However, apoptosis is the main cause of cell death induced by ischemia-reperfusion. Furthermore, previous studies have reported that lncRNA GAS5 has been revealed to be expressed at low levels in tumor tissues, which promotes apoptosis and inhibits cell growth (27). Therefore, a hypothesis was proposed, that
lncRNA GAS5 may be involved in the regulation of apoptosis induced by MIRI. By comparing and detecting the difference in 1ncRNA GAS5 expression in cardiomyocytes and tissue samples mediated by ischemia-reperfusion injury, it was revealed to be increased following ischemia-reperfusion, and these results supported the hypothesis. The present study then further investigated the potential function of lncRNA GAS5 in MIRI. By intervening in the expression of lncRNA GAS5, changes in myocardial necrosis markers, cell viability and cell apoptosis were observed. Through Hoechst staining and flow cytometry, it was revealed that silencing lncRNA GAS5 reduced the apoptosis rate. Therefore, the present study focused on the assessment of the apoptotic regulatory function of lncRNA GAS5. Apoptosis signal transduction molecules Bcl-2, Bax and caspase-3 are important signaling molecules in apoptosis (55). The expression levels of the above apoptotic proteins were further examined, and the conclusions were consistent with the aforementioned assumptions.

The present results are consistent with the experimental results from Liu et al (56); however, they did not conduct in-depth research on the regulatory mechanism, and the specific mechanism remains unclear. According to the reported mechanism of action of lncRNA GAS5 in other diseases, the present study focused on the regulation of PTEN by lncRNA GAS5. As previously stated, PTEN itself is a relatively classical protein that promotes apoptosis (45). Although the mechanisms of lncRNAs are complex, the biological function of lncRNA GAS5 is mostly mediated through the ceRNA mechanism, according to previous studies $(57,58)$. lncRNA GAS5 has also been reported to be involved in biological processes including apoptosis, through a variety of mechanisms associated with PTEN (36). It was hypothesized that lncRNA GAS5 may function through PTEN in apoptosis induced by MIRI. Following the intervention of IncRNA GAS5, the present study examined the expression of PTEN, and it was revealed that the inhibition of lncRNA GAS5 did reduce the high expression of PTEN in MIRI. Furthermore, through bioinformatics analysis, combined with the ceRNA mechanism, it was revealed that lncRNA GAS5 may function as an endogenous RNA, binding to miR-532-5p and regulating the expression of PTEN. To demonstrate this prediction, a luciferase reporter assay was performed on the predicted binding targets. The results confirmed the predictions. The expression levels of miR-532-5p were examined, and it was revealed that it was downregulated under HR treatment and had the opposite trend to the expression of 1ncRNA GAS5 and PTEN. miR-532-5p has been demonstrated to be able to alleviate hypoxia-induced apoptosis by targeting programmed cell death 4 in H9c2 cells (37). Furthermore, following miR-532-5p mimic and inhibitor treatment, it was revealed that HR-induced apoptosis was notably altered in the present study. In order to confirm the ceRNA mechanism, a rescue experiment was conducted. The present experiments further confirmed the regulatory function and mechanism of lncRNA GAS5 in MIRI.

In conclusion, as a pro-apoptotic factor, lncRNA GAS5 serves a function in MIRI, and it may reduce the apoptosis induced by injury to a certain extent. In-depth study suggested that lncRNA GAS5 may bind to miR-532-5p, so that miR-532-5p loses its regulatory effect on its target PTEN, resulting in the 
overexpression of PTEN and consequent inhibition of the PI3K/AKT pathway, thereby promoting apoptosis. Therefore, the inhibition of IncRNA GAS5 may improve cell survival, reduce the occurrence of apoptosis and ultimately alleviate MIRI. MIRI is a common clinical reperfusion complication. The present study may provide novel ideas for protecting against myocardial injury, but further research is still required.

\section{Acknowledgements}

Not applicable.

\section{Funding}

This study was supported by grants from the National Natural Science Foundation of China (grant nos. 81670320 and 31741047) and China Medical University Youth Backbone Support Program (grant no. QGZ2018021).

\section{Availability of data and materials}

The datasets used and analyzed during the current study are available from the corresponding author on reasonable request.

\section{Authors' contributions}

DJ, YH and NW conceived and designed the experiments. YH, FX and SL performed the experiments. YH and FX analyzed the data. YH wrote the paper. YH and FX revised the manuscript. All the authors read and approved the final paper.

\section{Ethics approval and consent to participate}

The experimental protocol was approved by the Institutional Ethics Committee of China Medical University.

\section{Patient consent for publication}

Not applicable.

\section{Competing interests}

The authors declare that they have no competing interests.

\section{References}

1. Gerczuk PZ and Kloner RA: An update on cardioprotection: A review of the latest adjunctive therapies to limit myocardial infarction size in clinical trials. J Am Coll Cardiol 59: 969-978, 2012.

2. Pollack A, Mohanty BD, Handa R, Looser PM, Fuster V, King S III and Sharma SK: Preventive stenting in acute myocardial infarction. JACC Cardiovase Interv 8: 131-138, 2015.

3. Majidi M, Kosinski AS, Al-Khatib SM, Lemmert ME, Smolders L, van Weert A, Reiber JH, Tzivoni D, Bär FW, Wellens HJ, et al: Reperfusion ventricular arrhythmia 'bursts' predict larger infarct size despite TIMI 3 flow restoration with primary angioplasty for anterior ST-elevation myocardial infarction. Eur Heart J 30: 757-764, 2009.

4. Taggart DP and Neubauer S: Incidence, predictors, and significance of abnormal cardiac enzyme rise in patients treated with bypass surgery in the arterial revascularization therapies study (ARTS). Circulation 106: e55-e56, 2002.
5. Eltzschig HK and Eckle T: Ischemia and reperfusion-from mechanism to translation. Nat Med 17: 1391-1401, 2011.

6. Garcia-Dorado D, Ruiz-Meana M,Inserte J, Rodriguez-Sinovas A and Piper HM: Calcium-mediated cell death during myocardial reperfusion. Cardiovasc Res 94: 168-180, 2012.

7. Koshinuma S, Miyamae M, Kaneda K, Kotani J and Figueredo VM: Combination of necroptosis and apoptosis inhibition enhances cardioprotection against myocardial ischemia-reperfusion injury. J Anesth 28: 235-241, 2014.

8. Vilahur $\mathrm{G}$ and Badimon L: Ischemia/reperfusion activates myocardial innate immune response: The key role of the toll-like receptor. Front Physiol 5: 496, 2014.

9. Tang L, Mo Y, Li Y, Zhong Y, He S, Zhang Y, Tang Y, Fu S, Wang $X$ and Chen A: Urolithin A alleviates myocardial ischemia/reperfusion injury via PI3K/Akt pathway. Biochem Biophys Res Commun 486: 774-780, 2017.

10. Ren GD, Cui Y, Li WL, Li FF and Han XY: Research on cardioprotective effect of irbesartan in rats with myocardial ischemia-reperfusion injury through MAPK-ERK signaling pathway. Eur Rev Med Pharmacol Sci 23: 5487-5494, 2019.

11. Bainey KR and Armstrong PW: Clinical perspectives on reperfusion injury in acute myocardial infarction. Am Heart J 167: 637-645, 2014.

12. Ong SB, Katwadi K, Kwek XY, Ismail NI, Chinda K, Ong SG and Hausenloy DJ: Non-coding RNAs as therapeutic targets for preventing myocardial ischemia-reperfusion injury. Expert Opin Ther Targets 22: 247-261, 2018.

13. Hombach S and Kretz M: Non-coding RNAs: Classification, biology and functioning. Adv Exp Med Biol 937: 3-17, 2016.

14. Qiu MT, Hu JW, Yin R and Xu L: Long noncoding RNA: An emerging paradigm of cancer research. Tumour Biol 34: 613-620, 2013.

15. Vitiello M, Tuccoli A and Poliseno L: Long non-coding RNAs in cancer: Implications for personalized therapy. Cell Oncol (Dordr) 38: 17-28, 2015.

16. Zangrando J, Zhang L, Vausort M, Maskali F, Marie PY, Wagner DR and Devaux Y: Identification of candidate long non-coding RNAs in response to myocardial infarction. BMC Genomics 15: 460, 2014.

17. Saddic LA, Sigurdsson MI, Chang TW, Mazaika E,Heydarpour M, Shernan SK, Seidman CE, Seidman JG, Aranki SF, Body SC and Muehlschlegel JD: The long noncoding RNA landscape of the ischemic human left ventricle. Circ Cardiovasc Genet 10: pii: e001534, 2017.

18. Gong LC, Xu HM, Guo GL, Zhang T, Shi JW and Chang C: Long non-coding RNA H19 protects $\mathrm{H} 9 \mathrm{c} 2$ cells against hypoxia-induced injury by targeting MicroRNA-139. Cell Physiol Biochem 44: 857-869, 2017.

19. Liu CY, Zhang YH, Li RB, Zhou LY, An T, Zhang RC, Zhai M, Huang Y, Yan KW, Dong YH, et al: LncRNA CAIF inhibits autophagy and attenuates myocardial infarction by blocking p53-mediated myocardin transcription. Nat Commun 9: 29, 2018.

20. Liu Y, Li G, Lu H, Li W, Li X, Liu H, Li X, Li T and Yu B: Expression profiling and ontology analysis of long noncoding RNAs in post-ischemic heart and their implied roles in ischemia/reperfusion injury. Gene 543: 15-21, 2014.

21. Schneider C, King RM and Philipson L: Genes specifically expressed at growth arrest of mammalian cells. Cell 54: 787-793, 1988.

22. Smith CM and Steitz JA: Classification of gas5 as a multi-small-nucleolar-RNA (snoRNA) host gene and a member of the 5'-terminal oligopyrimidine gene family reveals common features of snoRNA host genes. Mol Cell Biol 18: 6897-6909, 1998.

23. Kino T, Hurt DE, Ichijo T, Nader N and Chrousos GP: Noncoding RNA gas5 is a growth arrest- and starvation-associated repressor of the glucocorticoid receptor. Sci Signal 3: ra8, 2010.

24. Pickard MR, Mourtada-Maarabouni M and Williams GT: Long non-coding RNA GAS5 regulates apoptosis in prostate cancer cell lines. Biochim Biophys Acta 1832: 1613-1623, 2013.

25. Li J, Wang Y, Zhang CG, Xiao HJ, Hu JM and He JD: Effect of long non-coding RNA Gas5 on proliferation, migration, invasion and apoptosis of colorectal cancer HT-29 cell line (vol 18, 4, 2018). Cancer Cell Int 18: 4, 2018.

26. Cao Q, Wang N, Qi J, Gu Z and Shen H: Long noncoding RNAGAS5 acts as a tumor suppressor in bladder transitional cell carcinoma via regulation of chemokine (CC motif) ligand 1 expression. Mol Med Rep 13: 27-34, 2016.

27. Pickard MR and Williams GT: Molecular and cellular mechanisms of action of tumour suppressor GAS5 LncRNA. Genes (Basel) 6: 484-499, 2015. 
28. Kastenmayer RJ, Moore RM, Bright AL, Torres-Cruz R and Elkins WR: Select agent and toxin regulations: Beyond the Eighth edition of the guide for the care and use of laboratory animals. J Am Assoc Lab Anim Sci 51: 333-338, 2012.

29. Wu N, Li WN, Shu WQ and Jia DL: Protective effect of picroside II on myocardial ischemia reperfusion injury in rats. Drug Des Dev Ther 8: 545-554, 2014.

30. Kilkenny C, Browne WJ, Cuthill IC, Emerson M and Altman DG: Improving bioscience research reporting: The ARRIVE guidelines for reporting animal research. Vet Clin Path 41: 27-31, 2012

31. Murphy E and Steenbergen C: Mechanisms underlying acute protection from cardiac ischemia-reperfusion injury. Physiol Rev 88: 581-609, 2008.

32. Livak KJ and Schmittgen TD: Analysis of relative gene expression data using real-time quantitative PCR and the 2(T)(-Delta Delta C) method. Methods 25: 402-408, 2001.

33. Sun R and Zhang L: Long non-coding RNA MALAT1 regulates cardiomyocytes apoptosis after hypoxia/reperfusion injury via modulating miR-200a-3p/PDCD4 axis. Biomed Pharmacother 111: 1036-1045, 2019.

34. Zhang W, Li Y and Wang P: Long non-coding RNA-ROR aggravates myocardial ischemia/reperfusion injury. Braz J Med Biol Res 51: e6555, 2018.

35. Zeng B, Li Y, Jiang F, Wei C, Chen G, Zhang W, Zhao W and Yu D: LncRNA GAS5 suppresses proliferation, migration, invasion, and epithelial-mesenchymal transition in oral squamous cell carcinoma by regulating the miR-21/PTEN axis. Exp Cell Res 374: 365-373, 2019.

36. Tao H, Zhang JG, Qin RH, Dai C, Shi P, Yang JJ, Deng ZY and Shi KH: LncRNA GAS5 controls cardiac fibroblast activation and fibrosis by targeting miR-21 via PTEN/MMP-2 signaling pathway. Toxicology 386: 11-18, 2017.

37. Rehmsmeier M, Steffen P, Hochsmann M and Giegerich R: Fast and effective prediction of microRNA/target duplexes. RNA 10: $1507-1517,2004$.

38. Ma J, Zhang J, Wang Y, Long K, Wang X, Jin L, Tang Q, Zhu L, Tang G, Li X and Li M: MiR-532-5p alleviates hypoxia-induced cardiomyocyte apoptosis by targeting PDCD4. Gene 675: 36-43, 2018.

39. Agarwal V, Bell GW, Nam JW and Bartel DP: Predicting effective microRNA target sites in mammalian mRNAs. Elife 4, 2015

40. Han X, Shi H, Liu K, Zhong L, Wang F and You Q: Protective effect of gastrodin on myocardial ischemia-reperfusion injury and the expression of Bax and Bcl-2. Exp Ther Med 17: 4389-4394, 2019.

41. Liu S, Wu N, Miao J, Huang Z, Li X, Jia P, Guo Y and Jia D: Protective effect of morin on myocardial ischemia-reperfusion injury in rats. Int J Mol Med 42: 1379-1390, 2018.

42. Zhang BF, Jiang H, Chen J, Guo X, Li Y, Hu Q and Yang S: Nobiletin ameliorates myocardial ischemia and reperfusion injury by attenuating endoplasmic reticulum stress-associated apoptosis through regulation of the PI3K/AKT signal pathway. Int Immunopharmacol 73: 98-107, 2019.

43. Siddall HK, Warrell CE, Yellon DM and Mocanu MM Ischemia-reperfusion injury and cardioprotection: Investigating PTEN, the phosphatase that negatively regulates PI3K, using a congenital model of PTEN haploinsufficiency. Basic Res Cardiol 103: 560-568, 2008.
44. Ruan H, Li J, Ren S, Gao J, Li G, Kim R, Wu H and Wang Y: Inducible and cardiac specific PTEN inactivation protects ischemia/reperfusion injury. J Mol Cell Cardiol 46: 193-200, 2009.

45. Ke ZP, Xu P, Shi Y and Gao AM: MicroRNA-93 inhibits ischemia-reperfusion induced cardiomyocyte apoptosis by targeting PTEN. Oncotarget 7: 28796-28805, 2016.

46. Wei H, Yang Z and Lin B: Overexpression of long non coding RNA CA3-AS1 suppresses proliferation, invasion and promotes apoptosis via miRNA-93/PTEN axis in colorectal cancer. Gene 687: 9-15, 2019.

47. Cipolla GA, de Oliveira JC, Salviano-Silva A, Lobo-Alves SC, Lemos DS, Oliveira LC, Jucoski TS, Mathias C, Pedroso GA, Zambalde EP and Gradia DF: Long non-coding RNAs in multifactorial diseases: Another layer of complexity. Noncoding RNA 4: pii: E13, 2018

48. Wang KC and Chang HY: Molecular mechanisms of long noncoding RNAs. Mol Cell 43: 904-914, 2011.

49. Sanchez Calle A, Kawamura Y, Yamamoto Y, Takeshita F and Ochiya T: Emerging roles of long non-coding RNA in cancer. Cancer Sci 109: 2093-2100, 2018.

50. Smolle MA and Pichler M: The role of long non-coding RNAs in osteosarcoma. Noncoding RNA 4: pii: E7, 2018.

51. Weirick T, Militello G and Uchida S: Long non-coding RNAs in endothelial biology. Front Physiol 9: 522, 2018.

52. Wang S, Yu W, Chen J, Yao T and Deng F: LncRNA MALAT1 sponges miR-203 to promote inflammation in myocardial ischemia-reperfusion injury. Int J Cardiol 268: 245, 2018.

53. Williams GT, Hughes JP, Stoneman V, Anderson CL, McCarthy NJ, Mourtada-Maarabouni M, Pickard M, Hedge VL, Trayner I and Farzaneh F: Isolation of genes controlling apoptosis through their effects on cell survival. Gene Ther Mol Biol 10: 255-261, 2006.

54. Esmatabadi MJD, Motamedrad $M$ and Sadeghizadeh $M$ Down-regulation of lncRNA, GAS5 decreases chemotherapeutic effect of dendrosomal curcumin (DNC) in breast cancer cells Phytomedicine 42: 56-65, 2018.

55. Scorrano L and Korsmeyer SJ: Mechanisms of cytochrome c release by proapoptotic BCL-2 family members. Biochem Biophys Res Commun 304: 437-444, 2003.

56. Liu SD, Meng WX, Xu L, Chi C, Sun X and Liu HY: GAS5 promotes myocardial apoptosis in myocardial ischemia-reperfusion injury via upregulating LAS1 expression. Eur Rev Med Pharmacol Sci 22: 8447-8453, 2018.

57. Xue D, Zhou C, Lu H, Xu R, Xu X and He X: LncRNA GAS5 inhibits proliferation and progression of prostate cancer by targeting miR-103 through AKT/mTOR signaling pathway. Tumor Biol 37: 16187-16197, 2016.

58. Yang $\mathrm{W}$, Hong $\mathrm{L}, \mathrm{Xu} \mathrm{X}$, Wang $\mathrm{Q}$, Huang $\mathrm{J}$ and Jiang L: LncRNA GAS5 suppresses the tumorigenesis of cervical cancer by downregulating miR-196a and miR-205. Tumor Biol 39: $1010428317711315,2017$.

This work is licensed under a Creative Commons Attribution-NonCommercial-NoDerivatives 4.0 International (CC BY-NC-ND 4.0) License. 